\title{
The IsoGenie database: An interdisciplinary data management solution for ecosystems biology and environmental research
}

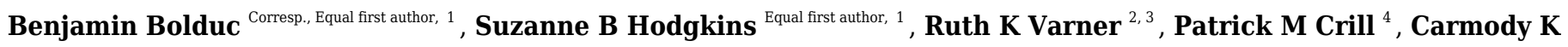 \\ McCalley $^{5}$, Jeffrey P Chanton ${ }^{6}$, Gene W Tyson ${ }^{7}$, William J Riley ${ }^{8}$, Michael Palace ${ }^{2,3}$, Melissa B Duhaime ${ }^{9}$, Moira A \\ Hough $^{10}$, Scott R Saleska ${ }^{10}$, Matthew B Sullivan ${ }^{1,11}$, Virginia I Rich ${ }^{\text {Corresp. } 1}$ \\ 1 Department of Microbiology, The Ohio State University, Columbus, Ohio, United States \\ 2 Earth Systems Research Center, Institute for the Study of Earth, Oceans and Space, University of New Hampshire, Durham, New Hampshire, United \\ States \\ 3 Department of Earth Sciences, College of Engineering and Physical Sciences, University of New Hampshire, Durham, New Hampshire, United States \\ 4 Department of Geological Sciences and Bolin Centre for Climate Research, Stockholm University, Stockholm, Sweden \\ 5 Thomas H. Gosnell School of Life Sciences, Rochester Institute of Technology, Rochester, New York, United States \\ 6 Department of Earth, Ocean, and Atmospheric Science, Florida State University, Tallahassee, Florida, United States \\ 7 Australian Centre for Ecogenomics, School of Chemistry and Molecular Biosciences, University of Queensland, Brisbane, Australia \\ 8 Climate and Ecosystem Sciences Division, Lawrence Berkeley National Laboratory, Berkeley, California, United States \\ 9 Department of Ecology and Evolutionary Biology, University of Michigan, Ann Arbor, Michigan, United States \\ 10 Department of Ecology and Evolutionary Biology, University of Arizona, Tucson, Arizona, United States \\ 11 Department of Civil, Environmental and Geodetic Engineering, The Ohio State University, Columbus, Ohio, United States \\ Corresponding Authors: Benjamin Bolduc, Virginia I Rich \\ Email address: bolduc.10@osu.edu, rich.270@osu.edu
}

Modern microbial and ecosystem sciences require diverse interdisciplinary teams that are often challenged in 'speaking' to one another due to different languages and data product types. Here we introduce the IsoGenie Database (IsoGenieDB;

https://isogenie-db.asc.ohio-state.edu/), a de novo developed data management and exploration platform, as a solution to this challenge of accurately representing and integrating heterogenous environmental and microbial data across ecosystem scales. The IsoGenieDB is a public and private data infrastructure designed to store and query data generated by the IsoGenie Project, a 10-year DOE-funded project focused on discovering ecosystem climate feedbacks in a thawing permafrost landscape. The IsoGenieDB provides (i) a platform for IsoGenie Project members to explore the project's interdisciplinary datasets across scales through the inherent relationships among data entities, (ii) a framework to consolidate and harmonize the datasets needed by the team's modelers, and (iii) a public venue that leverages the same spatially explicit, disciplinarily integrated data structure to share published datasets. The IsoGenieDB is also being expanded to cover the NASA-funded Archaea to Atmosphere (A2A) project, which scales the findings of IsoGenie to a broader suite of Arctic peatlands, via the umbrella A2A Database (A2A-DB). The IsoGenieDB's expandability and flexible architecture allow it to serve as an example 
ecosystems database. 
1 The IsoGenie Database: An interdisciplinary data 2 management solution for ecosystems biology and 3 environmental research

4

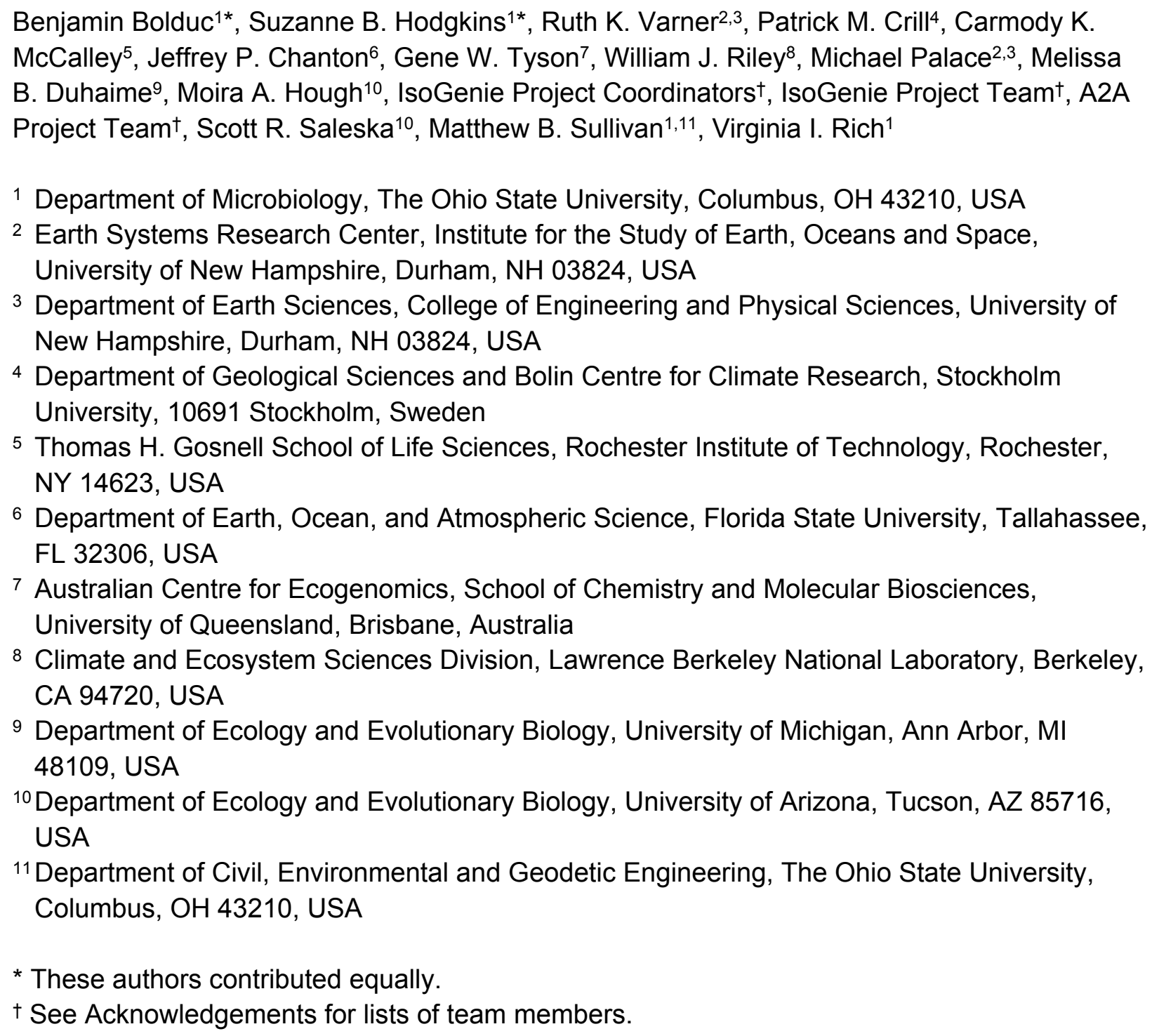

\section{Corresponding Authors:}

Virginia Rich ${ }^{1}$

Riffe Building Rm 934, 496 W 12th Ave Columbus, OH 43210, USA

Email address: rich.270@osu.edu

Benjamin Bolduc ${ }^{1}$

Riffe Building Rm 932, 496 W 12th Ave Columbus, OH 43210, USA

Email address: bolduc.10@osu.edu 


\section{Abstract}

Modern microbial and ecosystem sciences require diverse interdisciplinary teams that are often challenged in 'speaking' to one another due to different languages and data product types. Here we introduce the IsoGenie Database (IsoGenieDB; https://isogenie-db.asc.ohiostate.edu/), a de novo developed data management and exploration platform, as a solution to this challenge of accurately representing and integrating heterogenous environmental and microbial data across ecosystem scales. The IsoGenieDB is a public and private data infrastructure designed to store and query data generated by the IsoGenie Project, a 10-year DOE-funded project focused on discovering ecosystem climate feedbacks in a thawing permafrost landscape. The IsoGenieDB provides (i) a platform for IsoGenie Project members to explore the project's interdisciplinary datasets across scales through the inherent relationships among data entities, (ii) a framework to consolidate and harmonize the datasets needed by the team's modelers, and (iii) a public venue that leverages the same spatially explicit, disciplinarily integrated data structure to share published datasets. The IsoGenieDB is also being expanded to cover the NASA-funded Archaea to Atmosphere (A2A) project, which scales the findings of IsoGenie to a broader suite of Arctic peatlands, via the umbrella A2A Database (A2A-DB). The IsoGenieDB's expandability and flexible architecture allow it to serve as an example ecosystems database.

\section{Introduction}

Understanding and predicting the behavior of complex natural systems requires collecting and integrating data across multiple disciplines (Michener \& Jones, 2012). While data from a single discipline offer a limited view into the system as a whole, interdisciplinary data integration can provide independent and complementary views of the same phenomenon, as well as illuminate emergent non-additive behaviors (e.g., McCalley et al., 2014; Deng et al., 2017; Woodcroft \& Singleton et al., 2018; Wilson et al., 2019). Interdisciplinary, systems-scale integration of data-from isotopic and other geochemical measurements, to measures of microbial ecology and biochemistry, to climate data, to vegetation surveys and remote sensing-is essential to modeling and predicting biogeochemical cycling (Heffernan et al., 2014; Fei, Guo \& Potter, 2016; Rose et al., 2017).

First, some definitions are required before heterogenous data integration can be clearly discussed. For the purpose of this paper, data is broadly defined as information (usually numeric) collected using the scientific method, and a dataset is a structured collection of related data submitted by a person or lab as a cohesive entity. Examples of datasets include organic matter mass spectra with both compound-resolved and broad compound class relative abundances; a collection of DNA sequence raw reads, processed reads, and derived metagenome-assembled genomes (MAGs); and a timeseries of temperatures measured by a particular instrument at several locations. Datasets are not monolithic, but can be split or combined to address specific research questions; therefore, we use the term data product to refer to any structured collection of related data, whether a dataset, a piece of a dataset, or a collection of related datasets. Similarly structured data products from the same discipline (e.g., 
81 two different DNA sequence datasets from different labs) are referred to as being of the same 82 data product type (or, for datasets specifically, dataset type). Data format describes the 83 organization of a data product, and encompasses both file format (e.g., .csv, .fastq) and the 84 data organization within files of a given format (e.g., the specific columns present within a 85 spreadsheet). Data processing is any kind of quality control or calculation performed upon data, 86 including the conversion of raw data to ecologically-relevant "derived" products. This includes 87 processes such as simple blank correction, calibration of peak heights to determine chemical 88 concentrations, quality control of sequencing reads, and creation of vegetation maps from

89

90

91

92

93

94

95

96

97

98

99

100

101

102

103

104

105

106

107

108

109

110

111

112

113

114

115

116

117

118

119

120

121

122

123

124

remote sensing images. Processing may result in increased data quality, defined as the degree to which a data product represents an unbiased yet intuitively understandable snapshot of reality. Data integration is a specific type of processing in which different datasets-often across disciplines-are combined to enable exploration and synthesis. An organized framework containing data is a data structure, and its organizational paradigm is a data model. An integrative data structure usually requires creating small subsets of data based on location, timeframe, or other criteria, to allow recombination (integration); we refer to these subsets as data entitites, and these can be conceptualized as key:value pairs (e.g., a set of concentrations of chemical species for one sample). Finally, metadata describes information necessary to understand a data entity's meaning and origins. For our purposes, metadata falls under two categories: File metadata includes information about the source file from which a data entity derives, including the file path, contact information of the investigator(s), and variable definitions and units. Sampling metadata includes information about the physical origin of a data entity, such as the name of the site, GPS location, sampling date, and depth. Unlike file metadata, which is often stored in a "readme" file for a dataset, sampling metadata is typically stored within individual table rows under "descriptor" columns.

Organizing and connecting heterogenous data is not a new challenge, and a number of online repositories have been designed for this purpose, such as ESS-DIVE (https://essdive.lbl.gov/), NEON (https://www.neonscience.org/), LTER (https://ternet.edu/), PANGAEA (https://www.pangaea.de/), DataDryad (https://datadryad.org/), and DataONE (https://www.dataone.org/), among others. These systems are powerful and have their respective strengths, such as allowing datasets to be filtered based on keywords, locations, and other metadata. However, they do not integrate their data in a framework that allows scalable and detailed querying (for example, quickly extracting all water table and temperature data from multiple sites into a single table, for scaling of water table-temperature relationships from individual sites to a broader geographical range). The field of bioinformatics is further along in this regard: for molecular meta-omic data, numerous databases (e.g., MIGS/MIMS, MIMAS, IMG/M, GeneLab) (Hermida et al., 2006; Field et al., 2008; Gattiker et al., 2009; Chen et al., 2019; Ray et al., 2019) and integrative data management platforms (e.g., KBase, MOD-CO, ODG, GeNNet, BioKNO, MGV, OMMS, mixOmics) (Sujansky, 2001; Symons \& Nieselt, 2011; Perez-Arriaga et al., 2015; Yoon, Kim \& Kim, 2017; Costa et al., 2017; Rohart et al., 2017; Guhlin et al., 2017; Manzoni et al., 2018; Arkin et al., 2018; Brandizi et al., 2018; Rambold et al., 2019) have been developed, and often include standardization of sample metadata to enable efficient data integration. Notable among these are KBase (https://kbase.us/) (Arkin et al., 2018), which provides "apps" through which users can process their data in a framework that tracks processing steps ("provenance") in an accessible format, and MOD-CO (Rambold et al.,

Peer) reviewing PDF | (2019:10:42335:1:1:NEW 22 May 2020) 
125

126

127

128

129

130

131

132

133

134

135

136

137

138

139

140

141

142

143

144

145

146

147

148

149

150

151

152

153

154

155

156

157

158

159

160

161

162

163

164

165

166

167

168

2019), a bioinformatics data processing tool that includes a conceptual schema and data model to track metadata and workflows. However, these tools are built around molecular-scale biological data and do not attempt to describe the highly diverse, multi-scale heterogenous data typical of landscape-scale ecological studies. A few projects, to date, have attempted this: One of the most comprehensive of these is the ISA framework (https://www.isacommons.org/) (Sansone et al., 2012), a set of interrelated data annotation and analysis tools designed for life and environmental science. This framework is based around the ISA Abstract Model, a formalized metadata storage model that links samples, processes, and datasets using directed acyclic graphs stored in tabular or JSON format. However, the storage of graphs in separate table-like files precludes the fast querying capabilities of graph databases, which are more typically used for storing this type of data structure. Similarly, Barkstrom (2010) developed a system to track metadata relating to Earth science datasets' authorship and processing histories, but this system focuses mainly on metadata, rather than ability to query and explore the data themselves. The IndexMed Consortium (David et al., 2015) was formed to describe ecological data from the Mediterranean and attempted to integrate heterogenous data by linking multiple databases in a decentralized indexed framework. However, its decentralized model poses challenges for standardizing heterogenous data (which is needed for efficient crosscomparison), and its website no longer exists, nor is its codebase readily available to other teams. Several biodiversity data platforms (reviewed in Triebel, Hagedorn \& Rambold, 2012) have explored data sharing and cross-linkages, but the platforms used to store different dataset types (e.g., species distribution and sequencing data) remain separate.

Integrating data-and doing so across disciplines, beyond simple cataloguing and indexing - becomes critically important as data analysis methods become increasingly sophisticated (Michener \& Jones, 2012). As technological innovation allows, research is increasingly being performed across broader scales (e.g., from satellite data to processes at the micro and nanoscale) (Peters et al., 2008; Heffernan et al., 2014; Fei, Guo \& Potter, 2016; Rose et al., 2017; Jansen et al., 2019a), and new and more diverse data are being generated. This has prompted international efforts to develop standards that make data more Findable, Accessible, Interoperable, and Reusable among different labs (FAIR principles) (Wilkinson et al., 2016; Brandizi et al., 2018). These include programs, specifications, and ontologies such as EML (https://eml.ecoinformatics.org/) (Jones et al., 2019), ABCD (https://abcd.tdwg.org/) (Access to Biological Collection Data task group, 2007), INSPIRE (https://inspire.ec.europa.eu/), and ENVO (http://www.obofoundry.org/ontology/envo.html) (Buttigieg et al., 2013, 2016) developed for environmental data; the MIGS/MIMS, MIMARKS, and MIXS specifications (Field et al., 2008; Yilmaz et al., 2011) developed by the Genomic Standards Consortium (https://press3.mcs.anl.gov/gensc/) for biological sequencing data; and ISO standards (https://www.iso.org/standards.html) developed to standardize procedures for a broad range of applications including environmental management. Integrating and organizing highly diverse data, particularly when the data are derived across a broad set of disciplines, presents numerous technical and conceptual challenges.

Challenges to data integration primarily relate to data processing complexities. First, data from different disciplines often exist in different formats that do not compare directly, or the same measurement (e.g., gas flux) lacks standardization of units or sampling resolution across labs. Second, researchers start from raw measurements, but there are often numerous derived 
169

170

171

172

173

174

175

176

177

178

179

180

181

182

183

184

185

186

187

188

189

190

191

192

193

194

195

196

197

198

199

200

201

202

203

204

205

206

207

208

209

210

211

212

data products at different stages of quality control and processing, and these vary across disciplines. These derived data products may also be housed in distinct accepted data organization platforms; for example, for biomolecule sequence data, the Sequence Read Archive (SRA) (Leinonen et al., 2011) houses raw genomic and transcriptomic sequence reads, GenBank (Benson et al., 2012) houses MAGs and other derived data, and separate repositories exist for proteome data, including PRIDE (Martens et al., 2005; Vizcaíno et al., 2016) and ProteomeXchange (Vizcaíno et al., 2014). Third, beyond process-related quality control (to remove poor data), there is variation in data "quality levels" resulting from original experimental design and/or assumptions made during processing, and these vary across disciplines. For example, a chemical spectral dataset may first undergo blank and background corrections to improve quality level, and then be used to generate summary metrics that capture more ecologically relevant chemical properties, but these summary metrics may involve assumptions that compound empirical uncertainty (Ishii \& Boyer, 2012). Full understanding of these discipline-specific experimental quality standards is critical to integrating and comparing data across disciplines. Fourth, as technologies improve, data quality changes, which for long-term projects necessitates raw data retention to enable systematic reprocessing for modernized synthesis products. This can result in numerous versions of processed data, each with a different quality level, for the same set of raw measurements.

Given these challenges, an interdisciplinary data integration platform must include a standardized system for versioning datasets, labeling them by quality, and tracking data collection and processing workflows. While the first two tasks can be easily accomplished with standardized version numbers and quality labels, the high variety of data collection and processing workflows across disciplines necessitates a structure that can accommodate this variety without relying entirely on textual methods descriptions. The most straightforward way to accomplish this is for the data structure to mimic the physical relationships between physical entities: specifically, the relationships connecting physical entities (such as sampling sites, soil cores collected from and instruments located at these sites, and the resulting connections between data from these related entities) should be recapitulated in a data structure that maps these physical entities (and their connecting relationships) to corresponding data entities. Such a structure is not only intuitively understandable across disciplines, it also advances data organization in ways that facilitate exploration of ecological, organismal, and physicochemical interactions occurring both horizontally and vertically. This presents its own conceptual challenges, the most fundamental of which is how data relate within a data model or structure. In other words, while apples cannot strictly be compared to pears, traits they could plausibly share include collection location, assay technique, or properties of a higher-level classification; e.g., these fruit types can be represented as properties of "fruit" objects.

Here we sought to leverage diverse datasets generated by a large-scale international ecosystem science study, IsoGenie, to establish an integrative, interdisciplinary graph database platform, the IsoGenie Database (IsoGenieDB). This platform brings together ideas from existing frameworks (e.g., metadata provenance tracing: Barkstrom, 2010; ISA framework: Sansone et al., 2012; IndexMed Consortium: David et al., 2015; KBase: Arkin et al., 2018; MOD-CO: Rambold et al., 2019) by integrating data from multiple disciplines in a way that mirrors the physical relationships and workflow between data entities, while also allowing detailed exploration and fast querying of the data themselves.

Peer) reviewing PDF | (2019:10:42335:1:1:NEW 22 May 2020) 


\section{Materials \& Methods}

214 Assembly of interdisciplinary project datasets in need of integration

215 The IsoGenie Project (Figure 1) is a DOE-funded, interdisciplinary international team

216 studying ecosystem climate feedbacks of Stordalen Mire (68 $28^{\circ} \mathrm{N}, 1^{\circ} 03^{\prime} \mathrm{E}$; Figure $2 \mathrm{~A}$ ), a

217 thawing permafrost system located near Abisko, in northern Sweden. This long-term study site

218 offers historical data spanning more than a century, providing the foundation for IsoGenie's

219 systems characterization using modern technical approaches. Data from the IsoGenie and

220 related projects (Table 1; Figure 1A) span multiple levels of study, with temporal scales ranging

221 from minute- to decadal-resolution, and spatial scales ranging from nanoscale (e.g., elemental

222 composition of soil and pore water), to microscale (e.g., microbial composition and metabolic

223 processes), to macroscale (e.g., vegetation surveys and drone and satellite imagery) (Figure

224 1B). By integrating these myriad types of datasets, the project has characterized how thaw-

225 induced changes in hydrology and vegetation (Malmer et al., 2005; Johansson et al., 2006;

226 Bäckstrand et al., 2010; Palace et al., 2018) drive changes in organic matter (Hodgkins et al.,

227 2014, 2016; Wilson et al., 2017; Wilson \& Tfaily, 2018) and microbial and viral communities

228 (Mondav \& Woodcroft et al., 2014; Trubl et al., 2016, 2018, 2019; Singleton et al., 2018;

229 Emerson et al., 2018; Woodcroft \& Singleton et al., 2018; Martinez et al., 2019; Wilson et al.,

230 2019; Roux et al., 2019), giving rise to changes in carbon gas emissions (Wik et al., 2013, 2018;

231 Hodgkins et al., 2014, 2015; McCalley et al., 2014; Burke et al., 2019; Perryman et al., 2020),

232 and collectively these insights are allowing improvements in predictive models (Deng et al.,

233 2014, 2017; Chang et al., 2019b,a; Wilson et al., 2019).

234

235

The IsoGenie Project interfaces with several related projects at Stordalen Mire via interproject sharing of public datasets. These other projects include an NSF-funded Northern

236

237

238

239

240

241

242

243

244 Ecosystems Research for Undergraduates (REU) program, which focuses on mapping changing vegetation (Palace et al., 2018), lake sediment control on $\mathrm{CH}_{4}$ emissions from postglacial lakes (Wik et al., 2018), and emissions from thaw ponds (Burke et al., 2019) in the Mire. Another study, on changes in organic matter decomposition along several permafrost thaw transects (Malhotra \& Roulet, 2015; Malhotra et al., 2018), includes sites that have recently been incorporated into the extensive set of Stordalen sites sampled by IsoGenie. Finally, Stordalen Mire is one of five peatlands investigated by the NASA-funded Archaea to the Atmosphere (A2A) Project, whose goal is to upscale the IsoGenie Project's findings relating microbial communities and $\mathrm{CH}_{4}$ emissions to the pan-Arctic.

\section{Building a database to integrate across the heterogenous data generated by 246 IsoGenie}

The diversity of disciplines, dataset types, and spatial and temporal scales studied by

249

250

251

252

253 IsoGenie (Figure 1) presents a unique data integration challenge. We sought to address this challenge by developing the IsoGenie Database (IsoGenieDB), a novel data management and data exploration platform that integrates these heterogenous data into the same data structure. The IsoGenieDB is powered by Neo4j, a graph database platform that is also used by NASA, Walmart, eBay, Adobe, and numerous other well-established organizations, helping ensure its reliable longevity. The IsoGenieDB uses data entities and the inherent relationships between 
254

255

256

257

258

259

260

261

262

263

264

265

266

267

268

269

270

271

272

273

274

275

276

277

278

279

280

281

282

283

284

285

286

287

288

289

290

291

292

293

294

them as the basic building blocks of the database. These building blocks are used independent of data source, connecting all the data within one integrated structure.

The IsoGenieDB is built with a set of custom tools, available at https://bitbucket.org/MAVERICLab/isogeniedb-tools/, that use a combination of the py2neo Python package (https://py2neo.org) and Neo4j's own "Bolt" Python driver (https://neo4j.com). The fundamental design of the database follows a property graph model (Miller, 2013). Data entities are stored within nodes, which serve as the primary unit of organization. Nodes can have labels, which serve as a high-level means of categorizing nodes for fast access and classification (e.g., a node representing a bog soil core has the labels Bog and Core; hereafter, specific labels are referred to with capitalized words). Data and other detailed information are stored within the nodes as a set of key:value properties (e.g., Site__:Bog1 and Date :2013-0714). These properties can contain any numeric or text-based information (e.g., time, temperature, $\mathrm{pH}$ ), as well as links to flat files that store non-text information (e.g., core photographs, raw instrument trace outputs). Nodes are connected to other nodes through relationships (also known as edges), which store information about how the two nodes are related.

The IsoGenieDB leverages the inherent relationships within the data (e.g., commonalities in sampling location or measurement technique) to build the basic structure of the database. In the IsoGenieDB, most of the nodes are organized hierarchically based on location, date of sampling or field measurement, and general dataset type (e.g., gas fluxes, biogeochemical soil properties, or temperature timeseries), with the order of classification determined by the inherent nature of each data collection scheme (e.g., while soil cores and field sensors both exist at point locations, a soil core is collected on a particular day and can have data in several datasets across disciplines, whereas an installed field sensor typically only collects one dataset type over a span of many days). At the "root" of this structure is an Area node that represents the whole of Stordalen Mire. This Area node then branches to nodes representing increasingly specific spatial and/or temporal resolution, with highly-resolved Data nodes (representing small-scale spatiotemporally-separated data entities) finally appearing at the finest scales (Figure 3 ). This data organization paradigm mimics the way in which sampling schemes are conceptualized within IsoGenie and similar projects, with sampling entities (including field instruments such as temperature sensors, as well as physical samples such as cores) located within named sites, each with their own sampling intervals that can then be matched across dataset types based on the date of sampling. In contrast to the default grouping of data within separate datasets, this location- and time-based data model provides a straightforward way to integrate spatiotemporally related data from different disciplines, aiding in the exploration of emergent phenomena. While this base structure is tree-like, other conceptual patterns also exist and are traced with other relationship structures. To track dataset origin and file metadata, each Data node is linked to a Metadata node, which includes source file metadata such as file paths, authors, version, and data quality (Figure 3). More complex data processing pipelines, such as those used for -omics and spectral data processing, are described with networks of converging and diverging Data and Metadata nodes (Figure 4) (Barkstrom, 2010). 
295

296

297

298

299

300

301

302

303

304

305

306

307

308

309

310

311

312

313

314

315

316

317

318

319

320

321

322

323

324

325

326

327

328

329

330

331

332

333

334

\section{Results}

\section{Overview}

The IsoGenieDB, which has $>400,000$ nodes, combines the IsoGenie Project's data into an integrated structure that serves as a centralized resource for the project. This structure can be used to cross-reference different disciplinary datasets, providing a way to quickly retrieve custom subsets of data to address specific research questions. The IsoGenieDB also includes a public-facing web portal (https://isogenie-db.asc.ohio-state.edu/) that allows users to browse datasets using several methods, including a Queries page, a Downloads page, and a Map Interface. The IsoGenieDB is also being expanded to cover the NASA-funded A2A project via the Archaea to Atmosphere Database (A2A-DB), which overlaps with the IsoGenieDB (Figure 5) and is accessed through a separate web portal (https://a2a-db.asc.ohio-state.edu/; Map Interface shown in Figure 2A).

\section{Data exploration using the IsoGenieDB and its web platform}

\section{Interdisciplinary data queries}

One strength of the IsoGenieDB is its ability to cross-reference data between seemingly disparate datasets. Specifically, the integrated graph structure allows cross-disciplinary queries (such as relating atmospheric conditions to microbial composition within a single query), enabling detailed exploration of data from multiple datasets simultaneously. This contrasts with most existing data repositories, which tend to keep data in separate datasets and/or be geared towards a particular discipline, creating a need to manually filter files based on sampling metadata and then manually recombine the data to find such relationships. Also, by enabling direct traversal of the relationship structure, the graph database architecture allows complex searches to be performed several orders of magnitude faster than in relational databases (Neo4j, 2020). This helps researchers to more efficiently find and compare data from different disciplines, enabling the discovery of new phenomena. Queries to the database can be either simple or advanced.

Simple queries are those that select data based on labels. These queries can be performed via the web portal's Querying page, which provides both live querying (in development) and the results of saved or "cached" queries. For example, filtering based on the Core label (Figure S1) returns a table of all core nodes in the database, which can then be filtered based on the value of any column to allow the user to quickly retrieve core metadata. Querying based on multiple labels (available via live queries) provides another means of filtering the results (e.g., selection of both Core and Biogeochemistry labels returns cores that have biogeochemistry data).

Advanced queries are those that require the input of a custom Cypher command via Neo4j's built-in browser (Figure S2), allowing the user to filter data based on any custom criteria and then view the results as they appear within the graph structure itself. These might include, for example, identifying depths with $\mathrm{pH}<5$ that have microbial abundance data (this query would traverse the node structures for both the -omics data [Figure 4] and soil porewater data [Figure 3] that link to the same Depth nodes), or identifying multiple sites where specific 
335

336

337

338

339

340

341

342

343

344

345

346

347

348

349

350

351

352

353

354

355

356

357

358

359

360

361

362

363

364

365

366

367

368

369

370

371

372

373

374

microbial populations (as denoted with specific text) are present simultaneously over a specific time frame (which would involve searching for time-specific standardized sampling metadata among the Sequence nodes [Figure 4]); further examples are provided in the Discussion. The IsoGenieDB currently limits this advanced querying functionality to the database team (as the current command-line interface does not provide read-only access, nor does it restrict users from accessing private data from projects of which they are not members-for simple queries, the latter is accomplished on the back-end by filtering the query results to include only those nodes that are labeled with the project name [for the private portals] or as "Public" [for the public portals], as described in Figure 5). Future development will focus on ways to remove this restriction.

\section{Downloading data}

Publicly available data can be downloaded in their original format via the Data Downloads page, where datasets are listed as "packages" and made available for download (Figure S3). These packages include the names and contact information for the data contributors, as well as links to any associated publications and README files describing the dataset. For spreadsheets, these packages also include CSV versions that have been formatted and had their metadata nomenclature standardized by the database team for import into the IsoGenieDB. This not only facilitates transparency of the data import process, but also provides easily script-readable versions of these files that other project members can quickly import into $\mathrm{R}$, Matlab, or other analysis tools. Direct download of these raw, intermediate, and processed files is provided by the local web server, eliminating the need to query the database for retrieval.

Each download package also includes information on any updates or corrections to each dataset. As datasets are updated, they are assigned version numbers (formatted $x . y . z$ ) that separately track major $(x)$ and minor $(y)$ revisions by the original data generator, as well as versions of format-standardization performed by the database team ( $z$ ). Previous versions remain downloadable as zipped archives. Separate from version numbers, each dataset is also assigned a Quality Level (Table 2), which serves as an indicator of the degree to which the dataset has been subject to error checking, blank corrections, calibrations, peer review, and other quality control.

\section{Browsing sampling sites}

Sampling locations can be viewed through the Map Interface (Figure 2), which displays information from GPS-annotated Site and Core nodes as points on an interactive map. Each point can be clicked to display a popup, which lists the available types of datasets associated with that site or core (e.g., terrestrial geochemistry, autochamber measurements, etc.) along with photos of cores that can be downloaded. The displayed points can be filtered by habitat type classification, allowing selection of sites that belong to specific habitats. These points are overlain on an ultra-high-resolution drone image of a portion of the Mire (Palace et al., 2018).

\section{General information and outreach}

Beyond data integration and discovery, the IsoGenieDB website also enables outreach by showcasing the research of the IsoGenie Project members through several educational

Peer) reviewing PDF | (2019:10:42335:1:1:NEW 22 May 2020) 
375

376

377

378

379

380

381

382

383

384

385

386

387

388

389

390

391

392

393

394

395

396

397

398

399

400

401

402

403

404

405

406

407

408

409

410

411

412

413

414

415

pages (Figure S4). These include a repository of $>2000$ photos, which can be filtered by tags including general category (e.g. Core, People, Site, Landscape, etc.), habitat type (e.g. Palsa, Bog, Fen), site name, sampling year, and others. Additional pages include frequently asked questions relating to the database design, a list of project-related publications, and an interactive graphic of the IsoGenie Project members.

\section{Discussion}

\section{Advantages of the graph structure}

Unlike simple file repositories, the IsoGenieDB graph structure integrates disparate datasets into a single framework, while offering more flexible expansion and faster querying than relational databases. This allows one to use a single query to filter data from various sources based on custom criteria and extract only the data that matches that filter. In contrast, accomplishing the same task in existing environmental repositories (such as LTER or DataONE) often necessitates downloading multiple source files and then manually filtering them, a tedious process. Even if some built-in filtering is available, this capability is often limited in other databases (e.g., in JGl's IMG, although datasets can be filtered by habitat, they cannot be filtered by specific field site, and even the habitat labels are often unavailable or described incorrectly). Being able to filter data based on any of several criteria with just a few clicks (for simple queries) or a few lines of code (for advanced queries) enables more efficient data discovery, allowing investigators to explore new hypotheses on the fly.

The structure of the IsoGenieDB is also ideal for straightforwardly storing data at multiple processing stages. Many datasets include raw, processed, and summarized data, with the latter particularly helpful for interdisciplinary investigation, yet this multiplicity poses challenges for interdisciplinary data exploration. The IsoGenieDB addresses this problem by storing data in a framework that mirrors the data processing steps (Figure 4). Because each data entity's origin is explicitly reflected in the graph structure, database users can get a general idea of each data entity's origin and level of processing even for data from outside their main discipline. This contrasts with discipline-specific databases such as those in NCBI, which are built for bioinformaticians and can therefore pose a challenge for other scientists who are looking for specific types of data products (e.g., raw vs. processed reads, or $16 \mathrm{~S}$ data vs. metagenomes) for collaborative meta-analysis, but who may be unfamiliar with the names of the methods (e.g. pyrosequencing) used to generate these different data products.

Three querying examples below make use of these unique features:

1. (simple query) Retrieve metadata for all soil cores collected over the course of the project, regardless of which lab recorded the collection of the core (Figure S1). This is helpful for planning future field sampling priorities based on which sites and habitats have been over- or under-sampled in the past, without the need to manually consolidate this information from multiple field sheets. Although the ISA framework (https://www.isacommons.org/) (Sansone et al., 2012) specializes in tracking this type of metadata, it stores the metadata within tabular or JSON files, and thus does not make use of the fast querying capabilities of graph databases. 
416

417

418

419

420

421

422

423

424

425

426

427

428

429

430

431

432

433

434

435

436

437

438

439

440

441

442

443

444

445

446

447

448

449

450

451

452

453

454

455

456

457
2. (advanced query) Retrieve biogeochemistry data from collapsed palsa sites sampled on dates when the maximum air temperature recorded by ANS was $>25^{\circ} \mathrm{C}$ (Figure S2). When combined with similar queries that filter based on other temperature ranges, this could provide insight on possible temperaturedependent biogeochemical processes warranting further investigation. The data necessary for answering this type of question might be findable within a large environmental repository such as DataONE (https://www.dataone.org/); however, this data would most likely be in separate files, which would then need to be individually filtered to find the dates matching the temperature criteria and then to find the biogeochemistry data from samples collected on these dates. In contrast, the IsoGenieDB can quickly retrieve these matched data with a single query.

3. (advanced query) Find all samples where a specific microbe was found, based on the presence or absence of relationships connecting metagenomic data to a specific MAG, and then compare the biogeochemistry of these samples to those where that microbe was not found. This query makes direct use of the node/relationship structures corresponding to data processing steps, specifically those connecting physical samples to metagenomes to MAGs (Figure 4). To do this "traditionally", one would need to utilize BLAST to compare the specific MAG(s) to all of the samples, parse the results to identify non-matching sample(s), and then retrieve the sample metadata. Finally, these samples and their metadata outputs would need to have their biochemistry records retrieved. While relatively straightforward, this processing requires BLAST, a bioinformatic skillset to parse results, and numerous files stored in disparate formats (e.g. nonsample metadata, biochemistry records, sequencing files).

\section{Balancing efficiency, consistency, and flexibility of data import}

One of the challenges of building the IsoGenieDB has been data heterogeneity, which makes it difficult to efficiently import data at a granular level without making it too "messy" for the end user. More specifically, a balance is required between importing all data as-is (at the cost of reduced database searchability), or conversely, thoroughly standardizing all of the data (at the cost of more time-consuming data import and potential for human error). To balance these conflicting needs, the IsoGenieDB import code prioritizes standardizing metadata essential to determining each node's placement (e.g., site names, date formats, etc.). These essential metadata properties, denoted with double underscores (e.g., "Site__), are automatically propagated down the data classification tree (e.g., a node for a core section is automatically labeled with the core name and sampling date). This ensures that each node is given consistent labeling and placement regardless of dataset origin, allowing for greater ease and flexibility of querying the database. Meanwhile, more detailed measurement types and units remain in the original format contributed by each project member. Because the labels identifying node and relationship types are standardized across the database, data from different sources can be simultaneously queried and then exported as a unified data table, where the specific variables of interest can then be easily converted into common units for interdisciplinary data exploration (e.g., for principal components analysis or modeling inputs).

Peer] reviewing PDF | (2019:10:42335:1:1:NEW 22 May 2020) 
458

459

460

461

462

463

464

465

466

467

468

469

470

471

472

473

474

475

476

477

478

479

480

481

482

483

484

485

486

487

488

489

490

491

492

493

494

495

496

497

498

The use of standardized spatial and temporal information for node placement, combined with keeping the rest of the data in its original format, also allows the codebase for the database to be easily reused for new datasets with only minimal metadata standardization of the contributed data files. In a mid-size project such as IsoGenie ( $\$ 1 \mathrm{M} / \mathrm{yr}$ divided across 13 laboratories), ensuring a low upkeep burden is an essential feature of the IsoGenieDB.

\section{Future developments}

Improved cross-linkages between the graph database, web platform, and established data standards

Currently, the graph database and web portals share information (e.g. cached query results are regularly output to the Queries page, the Map Interface derives the map points and their associated properties from the sample metadata stored in graph nodes, and file metadata stored on the Data Downloads page matches that stored in the Metadata nodes of the graph database), but these components are not dynamically connected. Future improvements to the server architecture will enable the web server to communicate with the graph database in real time, allowing these pages to remain in sync with the graph database and to be automatically updated as new data are added.

As part of this automation, the metadata for individual datasets, listed in the Data Downloads page of the web portal, will be made to better conform with FAIR data standards. This will include functions to assign each dataset a DOI, to generate an Ecological Metadata Language (EML) file for each dataset (Jones et al., 2019) based on the file metadata stored in the graph database, and to create properties that store sample metadata using more broadlyused ontologies, such as Environmental Ontologies (ENVO) (Buttigieg et al., 2013, 2016), so that the data can be more readily usable for global analyses.

\section{Enhanced user accounts providing secure access to advanced querying}

Future improvements to the web portal will also make advanced querying available to all users. This will require the deployment of two major security upgrades, which will be implemented via new module(s) added to the back-end of the web portals:

1. Ensure that all user-submitted queries are read-only. This will involve three separate safeguards to greatly reduce the chances of unauthorized writes to the database: (a) refuse all Cypher statements that contain "write" keywords such as CREATE, DELETE, MERGE, and SET; (b) route the query to Neo4j through a read-only connection; and (c) automatically back up the database at regular intervals so that it can be restored if both of the previous safeguards fail (these regular backups are already in place).

2. Ensure that access to private data remains restricted to the project that generated it. This is specific to the case where a single database houses data from more than one project, as is the case for IsoGenie and A2A project collaboration, and would be relevant to other "nested" project sets where one project builds on the first and includes additional datasets that are not explicitly shareable with the personnel of the nested project. Project-specific access is currently being accomplished for simple queries by including the labels 
499

500

501

502

503

504

505

506

507

508

509

510

511

512

513

514

515

516

517

518

519

520

521

522

523

524

525

526

527

528

529

530

531

532

533

534

535

536

537

538

539

540

"IsoGenie", "A2A", and/or "Public" in the search criteria for the pre-generated Cypher MATCH queries requested from the private IsoGenie, private A2A, and public web portals, respectively (these labels are added during data import; Figure 5). Controlling data access for advanced queries would make use of these same labels, and might be accomplished in the following ways: (a) create entirely separate graph databases for each user group, which would be regularly updated, based on project-access node labels in the current shared database; (b) use string replacement to add these labels to all MATCH clauses submitted by users; or (c) develop an "intermediate query" interface, which would keep the same back-end access label filtering used for simple queries, while allowing users to choose among a greatly expanded set of querying options.

\section{Storing experimental results as graph structure}

The graph structure of the IsoGenieDB not only more fully allows researchers to address their own discipline-specific questions, but also can facilitate the identification of emergent relationships in the data. Currently, all data in the IsoGenieDB are stored as properties within nodes that are organized based on sampling and experimental schemes. While this makes possible the simultaneous querying and export of multiply sourced data, other tools still must be used to explore ecological relationships within this data. A future goal of the IsoGenieDB is therefore to explicitly encode experimental results in the broader node structure itself (e.g., to add relationships connecting plant species to sites, or microbes to the chemical compounds they metabolize), allowing the direct use of the graph structure for network-based data mining (David et al., 2015; Yoon, Kim \& Kim, 2017).

\section{Sharing across projects}

Because the graph database framework allows easy addition of new sites and dataset types, this allows the database to be expanded to cover multiple projects with overlapping datasets. This functionality is currently being implemented with the A2A-DB, which includes a subset of the IsoGenie Project's data, along with data from the A2A project's other study sites (each of which has its own Area node). The IsoGenieDB and A2A-DB share the same back-end graph database, in which separate access for each project and the general public is controlled with dedicated node labels (IsoGenie, A2A, and Public) (Figure 5). This system offers the advantage that updates to shared data from one project are automatically accessible by other project(s) that have access to the same data, while separately coded web interfaces (with separate sets of authorized users) prevent private datasets from being shared outside their respective projects.

Another goal of the IsoGenieDB is for its import code to be more easily reusable by other projects, such that other groups can easily generate their own databases based on the IsoGenieDB's basic design. The codebase already separates the scripts used for datasetspecific header standardization from those used for import to the database, allowing the import scripts to be reusable for different datasets of similar structure with minimal modification. Future development will convert these import scripts into functions that can accept custom parameters for specific node labels and other high-level metadata, thus removing the need for these small modifications to the scripts. Over the longer term, these functions may be further consolidated

Peer) reviewing PDF | (2019:10:42335:1:1:NEW 22 May 2020) 
541 into a single function that can create node trees (Figure 3) with any arbitrary number of "levels," 542 which would be read from structured "node map" objects (one of which would be associated 543 with each dataset). By making it easier for other projects to adapt the IsoGenieDB import code 544 to suit their own data, these developments will improve the ability of the IsoGenieDB to serve as 545 a model for other ecosystems databases.

\section{6}

547

548

549

550

551

552

553

554

555

556

557

558

559

560

561

562

563

564

565

566

567

568

569

570

571

572

\section{3}

574

575

576

577

578

579

\section{Conclusions}

The IsoGenieDB addresses the challenges of interdisciplinary data integration by organizing large, interdisciplinary project data into a novel platform that can incorporate nearly any type of dataset, and that allows scientists to explore data through the inherent conceptual relationships between data entities both within and across datasets. While the graph structure allows for the flexible integration of heterogenous datasets, the use of standardized labels and relationship types ensures that the metadata describing each dataset remains relatively homogenous throughout the database, allowing detailed querying across all these multi-scale elements. Querying the data for specific features of interest that were not associated during initial collection or primary analyses allows discovery of new relationships. By storing all IsoGenie Project data in this integrated framework, and being able to augment with data from various other sources (such as the 100-year datasets from ANS (Callaghan et al., 2010; Jonasson et al., 2012) and paleoclimate records (Kokfelt et al., 2009, 2010)), the IsoGenieDB is capable of describing all elements of an ecosystem-from nanoscale to planetary, from microseconds to centuries, and from microbes and viruses to plants and gases. This structure also lends itself to the automated generation of metadata in more broadly-used nomenclature and format standards (as is being planned for future improvements), which will allow users to interact more dynamically with the database and facilitate FAIRer data sharing via the web portal. Because of these features, the IsoGenieDB can serve as an example ecosystems database for managing and storing nearly any type and amount of data.

\section{Acknowledgements}

We gratefully acknowledge a decade of support from the Abisko Naturvetenskapliga Station (Abisko Scientific Research Station, Sweden) for annual field campaigns and on-site experiments, and Station member Annika Kristoffersson for contribution of Station climate data to the IsoGenieDB. We also thank Justin Slauson at the Ohio State University College of Arts and Sciences Technology Services (ASC-Tech) for assisting with initial establishment and ongoing technical support for the IsoGenieDB and A2A-DB web server.

\section{Consortium author lists}

The IsoGenie Project Coordinators are: Scott Saleska (University of Arizona), Virginia Rich (The Ohio State University), Patrick Crill (Stockholm University), Jeff Chanton (Florida State University), Gene Tyson (University of Queensland), Ruth Varner (University of New Hampshire), Matthew Sullivan (The Ohio State University), Steve Frolking (University of New Hampshire), Changsheng Li (University of New Hampshire), Eoin Brodie (Lawrence Berkeley National Lab), and William Riley (Lawrence Berkeley National Lab).

Peer] reviewing PDF | (2019:10:42335:1:1:NEW 22 May 2020) 
580

581

582

583

584

585

586

587

588

589

590

591

592

593

594

595

596

597

598

599

600

601

602

603

604

605

606

607

608

609

610

611

612

613

614

615

616

617

618

619

620

621

622

623
The IsoGenie Project Team includes the Coordinators and the following members:

- Field Teams: Darya Anderson (University of Arizona), Hanna Axén (Abisko Scientific Research Station), Kathryn Bennett (University of New Hampshire), Jeff Chanton (Florida State University), Patrick Crill (Stockholm University), Sky Dominguez (University of Arizona), Jessica Ernakovich (University of New Hampshire), Florencia Fahnestock (University of New Hampshire), Steve Frolking (University of New Hampshire), Anthony J. Garnello (current location: Northern Arizona University), Suzanne Hodgkins (The Ohio State University), Moira Hough (University of Arizona), Joachim Jansen (current location: Stockholm University), Robert Jones (current location: Cold Regions Research and Engineering Laboratory), Eun-Hae Kim (current location: Ventana Medical Systems), Changsheng Li (University of New Hampshire), Tyler Logan (current location: Numbers 4 Nonprofits), Tamara Marcus (University of New Hampshire), Samantha McCabe (The Ohio State University), Carmody McCalley (current location: Rochester Institute of Technology), Amelia McClure (current location: Horsley Witten Group), Rhiannon Mondav (current location: Uppsala University), Apryl Perry (University of New Hampshire), Nicole Raab (current location: Battelle), Virginia Rich (The Ohio State University), Scott Saleska (University of Arizona), Kristina Solheim (current location: Viosimo, LLC), Peter Tansey (University of New Hampshire), Gareth Trubl (current location: Lawrence Livermore National Laboratory), Gene Tyson (University of Queensland), Ruth Varner (University of New Hampshire), Martin Wik (Stockholm University), and Rachel Wilson (Florida State University).

- Laboratory \& Analytic Teams: Darya Anderson (University of Arizona), Ben Bolduc (The Ohio State University), Joel Boyd (University of Queensland), Eoin Brodie (Lawrence Berkeley National Lab), Sophia Burke (University of New Hampshire), Kuang-Yu Chang (Lawrence Berkeley National Lab), Jeff Chanton (Florida State University), William Cooper (Florida State University), Alex Cory (Florida State University), Patrick Crill (Stockholm University), Dylan Cronin (The Ohio State University), Kelsey Crossen (current location: Tehachapi Unified School District), Jia Deng (University of New Hampshire), Sky Dominguez (University of Arizona), Ellen Dorrepaal (Umeå University), Joanne Emerson (current location: University of California, Davis), Paul Evans (University of Queensland), Florencia Fahnestock (University of New Hampshire), Steve Frolking (University of New Hampshire), Anthony J. Garnello (current location: Northern Arizona University), Suzanne Hodgkins (The Ohio State University), Robert Hoelzle (University of Queensland), Moira Hough (University of Arizona), Beth Huettel (Florida State University), Bonnie Hurwitz (University of Arizona), Robert Jones (current location: Cold Regions Research and Engineering Laboratory), Ulas Karaoz (Lawrence Berkeley National Lab), Eun-Hae Kim (current location: Ventana Medical Systems), Josh Kolengowski (The Ohio State University), Changsheng Li (University of New Hampshire), Fen Li (The Ohio State University), Tamara Marcus (University of New Hampshire), Miguel 
624

625

626

627

628

629

630

631

632

633

634

635

636

637

638

639

640

641

642

643

644

645

646

647

648

649

650

651

652

653

654

655

656

657

658

659

660

661

662

663

664
Martinez (current location: Ensenada Center for Scientific Research and Higher Education), Samantha McCabe (The Ohio State University), Carmody McCalley (current location: Rochester Institute of Technology), Amelia McClure (current location: Horsley Witten Group), Rhiannon Mondav (current location: Uppsala University), Isabel Morales (The Ohio State University), Duc Nguyen (current location: Linköping University), Clarice Perryman (University of New Hampshire), Nicole Raab (current location: Battelle), Virginia Rich (The Ohio State University), William Riley (Lawrence Berkeley National Lab), Scott Saleska (University of Arizona), Caitlin Singleton (University of Queensland), Matthew Sullivan (The Ohio State University), Malak Tfaily (University of Arizona), Gareth Trubl (current location: Lawrence Livermore National Laboratory), Gene Tyson (University of Queensland), Ruth Varner (University of New Hampshire), Nathan VerBerkmoes (current location: STEM Educational Consultations, Inc.), S. Rose Vining (current location: State of Alaska Department of Environmental Conservation) ,Rick Wehr (University of Arizona), Martin Wik (Stockholm University), Rachel Wilson (Florida State University), Katelyn Winters (The Ohio State University), Ben Woodcroft (University of Queensland), Gregory Zane (current location: University of Washington), and Ahmed Zayed (The Ohio State University).

The Archaea to Atmosphere (A2A) Project Team includes the following members: Ben Bolduc (The Ohio State University), Rob Braswell (Applied Geosolutions), Sophia Burke (University of New Hampshire), Eleanor Campbell (University of New Hampshire), Patrick Crill (Stockholm University), Jessica DelGreco (University of New Hampshire), Jia Deng (University of New Hampshire), Florencia Fahnestock (University of New Hampshire), Justin Fisk (Applied Geosolutions), Christina Herrick (University of New Hampshire), Suzanne Hodgkins (The Ohio State University), L. Jamie Lamit (Syracuse University), Carmody McCalley (Rochester Institute of Technology), Michael Palace (University of New Hampshire), Apryl Perry (University of New Hampshire), Clarice Perryman (University of New Hampshire), Virginia Rich (The Ohio State University), Joanne Shorter (Aerodyne Research), Franklin Sullivan (University of New Hampshire), Nathan Torbick (Applied Geosolutions), Ruth Varner (University of New Hampshire), and Beth Ziniti (Applied Geosolutions).

\section{Code and Data Availability}

The code used to interact with the IsoGenieDB, including standardizing and importing data and performing queries, is available at https://bitbucket.org/MAVERICLab/isogeniedbtools/. The IsoGenie Database, and all public data deposited therein, can be accessed at https://isogenie-db.asc.ohio-state.edu/. The A2A Database and associated public data can be accessed at https://a2a-db.asc.ohio-state.edu/.

\section{References}

Access to Biological Collection Data task group. 2007.Access to Biological Collection Data (ABCD), Version 2.06. Available at http://www.tdwg.org/standards/115 (accessed March $31,2020)$.

Peer] reviewing PDF | (2019:10:42335:1:1:NEW 22 May 2020) 
665

666

667

668

669

670

671

672

673

674

675

676

677

678

679

680

681

682

683

684

685

686

687

688

689

690

691

692

693

694

695

696

697

698

699

700

701

702

703

704

Arkin AP, Cottingham RW, Henry CS, Harris NL, Stevens RL, Maslov S, Dehal P, Ware D, Perez F, Canon S, Sneddon MW, Henderson ML, Riehl WJ, Murphy-Olson D, Chan SY, Kamimura RT, Kumari S, Drake MM, Brettin TS, Glass EM, Chivian D, Gunter D, Weston DJ, Allen BH, Baumohl J, Best AA, Bowen B, Brenner SE, Bun CC, Chandonia J-M, Chia J-M, Colasanti R, Conrad N, Davis JJ, Davison BH, DeJongh M, Devoid S, Dietrich E, Dubchak I, Edirisinghe JN, Fang G, Faria JP, Frybarger PM, Gerlach W, Gerstein M, Greiner A, Gurtowski J, Haun HL, He F, Jain R, Joachimiak MP, Keegan KP, Kondo S, Kumar V, Land ML, Meyer F, Mills M, Novichkov PS, Oh T, Olsen GJ, Olson R, Parrello B, Pasternak S, Pearson E, Poon SS, Price GA, Ramakrishnan S, Ranjan P, Ronald PC, Schatz MC, Seaver SMD, Shukla M, Sutormin RA, Syed MH, Thomason J, Tintle NL, Wang D, Xia F, Yoo H, Yoo S, Yu D. 2018. KBase: The United States Department of Energy Systems Biology Knowledgebase. Nature Biotechnology 36:566-569. DOI: $10.1038 / \mathrm{nbt} .4163$.

Bäckstrand K, Crill PM, Jackowicz-Korczyñski M, Mastepanov M, Christensen TR, Bastviken D. 2010. Annual carbon gas budget for a subarctic peatland, Northern Sweden.

Biogeosciences 7:95-108. DOI: 10.5194/bg-7-95-2010.

Bäckstrand K, Crill PM, Mastepanov M, Christensen TR, Bastviken D. 2008a. Non-methane volatile organic compound flux from a subarctic mire in Northern Sweden. Tellus B: Chemical and Physical Meteorology 60:226-237. DOI: 10.1111/j.16000889.2007.00331.x.

Bäckstrand K, Crill PM, Mastepanov M, Christensen TR, Bastviken D. 2008b. Total hydrocarbon flux dynamics at a subarctic mire in northern Sweden. Journal of Geophysical Research: Biogeosciences 113:G03026. DOI: 10.1029/2008JG000703.

Barkstrom BR. 2010. A mathematical framework for earth science data provenance tracing. Earth Science Informatics 3:167-196. DOI: 10.1007/s12145-010-0057-0.

Benson DA, Cavanaugh M, Clark K, Karsch-Mizrachi I, Lipman DJ, Ostell J, Sayers EW. 2012. GenBank. Nucleic Acids Research 41:D36-D42. DOI: 10.1093/nar/gks1195.

Brandizi M, Singh A, Rawlings C, Hassani-Pak K. 2018. Towards FAIRer biological knowledge networks using a hybrid linked data and graph database approach. Journal of Integrative Bioinformatics 15:20180023. DOI: 10.1515/jib-2018-0023.

Burke SA, Wik M, Lang A, Contosta AR, Palace M, Crill PM, Varner RK. 2019. Long term measurements of methane ebullition from thaw ponds. Journal of Geophysical Research: Biogeosciences 124. DOI: 10.1029/2018JG004786.

Buttigieg P, Morrison N, Smith B, Mungall CJ, Lewis SE, the ENVO Consortium. 2013. The environment ontology: contextualising biological and biomedical entities. Journal of Biomedical Semantics 4:43. DOI: 10.1186/2041-1480-4-43.

Buttigieg PL, Pafilis E, Lewis SE, Schildhauer MP, Walls RL, Mungall CJ. 2016. The environment ontology in 2016: bridging domains with increased scope, semantic density, and interoperation. Journal of Biomedical Semantics 7:57. DOI: 10.1186/s13326-0160097-6.

Peer] reviewing PDF | (2019:10:42335:1:1:NEW 22 May 2020) 
705

706

707

708

709

710

711

712

713

714

715

716

717

718

719

720

721

722

723

724

725

726

727

728

729

730

731

732

733

734

735

736

737

738

739

740

741

742

743

744

745
Callaghan TV, Bergholm F, Christensen TR, Jonasson C, Kokfelt U, Johansson M. 2010. A new climate era in the sub-Arctic: Accelerating climate changes and multiple impacts. Geophysical Research Letters 37:L14705. DOI: 10.1029/2009GL042064.

Chang K, Riley WJ, Brodie EL, McCalley CK, Crill PM, Grant RF. 2019a. Methane production pathway regulated proximally by substrate availability and distally by temperature in a high-latitude mire complex. Journal of Geophysical Research: Biogeosciences 124:3057-3074. DOI: 10.1029/2019JG005355.

Chang K-Y, Riley WJ, Crill PM, Grant RF, Rich VI, Saleska SR. 2019b. Large carbon cycle sensitivities to climate across a permafrost thaw gradient in subarctic Sweden. The Cryosphere 13:647-663. DOI: 10.5194/tc-13-647-2019.

Chen I-MA, Chu K, Palaniappan K, Pillay M, Ratner A, Huang J, Huntemann M, Varghese N, White JR, Seshadri R, Smirnova T, Kirton E, Jungbluth SP, Woyke T, Eloe-Fadrosh EA, Ivanova NN, Kyrpides NC. 2019. IMG/M v.5.0: an integrated data management and comparative analysis system for microbial genomes and microbiomes. Nucleic Acids Research 47:D666-D677. DOI: 10.1093/nar/gky901.

Costa RL, Gadelha L, Ribeiro-Alves M, Porto F. 2017. GeNNet: an integrated platform for unifying scientific workflows and graph databases for transcriptome data analysis. PeerJ 5:e3509. DOI: 10.7717/peerj.3509.

David R, Feral J-P, Gachet S, Dias A, Blanpain C, Lecubin J, Diaconu C, Surace C, Gibert K. 2015. A first prototype for indexing, visualizing and mining heterogeneous data in Mediterranean ecology within the IndexMed consortium interdisciplinary framework. In: 2015 11th International Conference on Signal-Image Technology \& Internet-Based Systems (SITIS). Bangkok, Thailand: IEEE, 232-239. DOI: 10.1109/SITIS.2015.119.

Deng J, Li C, Frolking S, Zhang Y, Bäckstrand K, Crill P. 2014. Assessing effects of permafrost thaw on $C$ fluxes based on multiyear modeling across a permafrost thaw gradient at Stordalen, Sweden. Biogeosciences 11:4753-4770. DOI: 10.5194/bg-11-4753-2014.

Deng J, McCalley CK, Frolking S, Chanton J, Crill P, Varner R, Tyson G, Rich V, Hines M, Saleska SR, Li C. 2017. Adding stable carbon isotopes improves model representation of the role of microbial communities in peatland methane cycling. Journal of Advances in Modeling Earth Systems 9:1412-1430. DOI: 10.1002/2016MS000817.

Emerson JB, Roux S, Brum JR, Bolduc B, Woodcroft BJ, Jang HB, Singleton CM, Solden LM, Naas AE, Boyd JA, Hodgkins SB, Wilson RM, Trubl G, Li C, Frolking S, Pope PB, Wrighton KC, Crill PM, Chanton JP, Saleska SR, Tyson GW, Rich VI, Sullivan MB. 2018. Host-linked soil viral ecology along a permafrost thaw gradient. Nature Microbiology 3:870-880. DOI: 10.1038/s41564-018-0190-y.

Fei S, Guo Q, Potter K. 2016. Macrosystems ecology: novel methods and new understanding of multi-scale patterns and processes. Landscape Ecology 31:1-6. DOI: 10.1007/s10980015-0315-0.

Field D, Garrity G, Gray T, Morrison N, Selengut J, Sterk P, Tatusova T, Thomson N, Allen MJ, Angiuoli SV, Ashburner M, Axelrod N, Baldauf S, Ballard S, Boore J, Cochrane G, Cole J, Dawyndt P, De Vos P, dePamphilis C, Edwards R, Faruque N, Feldman R, Gilbert J, 
746

747

748

749

750

751

752

753

754

755

756

757

758

759

760

761

762

763

764

765

766

767

768

769

770

771

772

773

774

775

776

777

778

779

780

781

782

783

784

785

786

Gilna P, Glöckner FO, Goldstein P, Guralnick R, Haft D, Hancock D, Hermjakob H, Hertz-Fowler C, Hugenholtz P, Joint I, Kagan L, Kane M, Kennedy J, Kowalchuk G, Kottmann R, Kolker E, Kravitz S, Kyrpides N, Leebens-Mack J, Lewis SE, Li K, Lister AL, Lord P, Maltsev N, Markowitz V, Martiny J, Methe B, Mizrachi I, Moxon R, Nelson K, Parkhill J, Proctor L, White O, Sansone S-A, Spiers A, Stevens R, Swift P, Taylor C, Tateno Y, Tett A, Turner S, Ussery D, Vaughan B, Ward N, Whetzel T, San Gil I, Wilson G, Wipat A. 2008. The minimum information about a genome sequence (MIGS) specification. Nature Biotechnology 26:541-547. DOI: 10.1038/nbt1360.

Garnello AJ. 2017. Establishing the role of digital repeat photography in understanding phenology and carbon cycling in a subarctic peatland. Master's thesis Thesis. Tucson, AZ: University of Arizona.

Gattiker A, Hermida L, Liechti R, Xenarios I, Collin O, Rougemont J, Primig M. 2009. MIMAS 3.0 is a multiomics information management and annotation system. BMC Bioinformatics 10:151. DOI: 10.1186/1471-2105-10-151.

Guhlin J, Silverstein KAT, Zhou P, Tiffin P, Young ND. 2017. ODG: Omics database generator a tool for generating, querying, and analyzing multi-omics comparative databases to facilitate biological understanding. BMC Bioinformatics 18:367. DOI: 10.1186/s12859017-1777-7.

Heffernan JB, Soranno PA, Angilletta MJ, Buckley LB, Gruner DS, Keitt TH, Kellner JR, Kominoski JS, Rocha AV, Xiao J, Harms TK, Goring SJ, Koenig LE, McDowell WH, Powell H, Richardson AD, Stow CA, Vargas Rodrigo, Weathers KC. 2014. Macrosystems ecology: understanding ecological patterns and processes at continental scales. Frontiers in Ecology and the Environment 12:5-14. DOI: 10.1890/130017.

Hermida L, Schaad O, Demougin P, Descombes P, Primig M. 2006. MIMAS: an innovative tool for network-based high density oligonucleotide microarray data management and annotation. BMC Bioinformatics 7:190. DOI: 10.1186/1471-2105-7-190.

Hodgkins SB. 2016. Changes in organic matter chemistry and methanogenesis due to permafrost thaw in a subarctic peatland. Dissertation Thesis. Tallahassee, FL: The Florida State University.

Hodgkins SB, Chanton JP, Langford LC, McCalley CK, Saleska SR, Rich VI, Crill PM, Cooper WT. 2015. Soil incubations reproduce field methane dynamics in a subarctic wetland. Biogeochemistry 126:241-249. DOI: 10.1007/s10533-015-0142-z.

Hodgkins SB, Richardson CJ, Dommain R, Wang H, Glaser PH, Verbeke B, Winkler BR, Cobb AR, Rich VI, Missilmani M, Flanagan N, Ho M, Hoyt AM, Harvey CF, Vining SR, Hough MA, Moore TR, Richard PJH, De La Cruz FB, Toufaily J, Hamdan R, Cooper WT, Chanton JP. 2018. Tropical peatland carbon storage linked to global latitudinal trends in peat recalcitrance. Nature Communications 9:3640. DOI: 10.1038/s41467-018-06050-2.

Hodgkins SB, Tfaily MM, McCalley CK, Logan TA, Crill PM, Saleska SR, Rich VI, Chanton JP. 2014. Changes in peat chemistry associated with permafrost thaw increase greenhouse gas production. Proceedings of the National Academy of Sciences of the United States of America 111:5819-5824. DOI: 10.1073/pnas.1314641111.

Peer] reviewing PDF | (2019:10:42335:1:1:NEW 22 May 2020) 
787

788

789

790

791

792

793

794

795

796

797

798

799

800

801

802

803

804

805

806

807

808

809

810

811

812

813

814

815

816

817

818

819

820

821

822

823

824

825

826

Hodgkins SB, Tfaily MM, Podgorski DC, McCalley CK, Saleska SR, Crill PM, Rich VI, Chanton JP, Cooper WT. 2016. Elemental composition and optical properties reveal changes in dissolved organic matter along a permafrost thaw chronosequence in a subarctic peatland. Geochimica et Cosmochimica Acta 187:123-140. DOI: 10.1016/j.gca.2016.05.015.

Holst T, Arneth A, Hayward S, Ekberg A, Mastepanov M, Jackowicz-Korczynski M, Friborg T, Crill PM, Bäckstrand K. 2010. BVOC ecosystem flux measurements at a high latitude wetland site. Atmospheric Chemistry and Physics 10:1617-1634. DOI: 10.5194/acp-101617-2010.

Ishii SKL, Boyer TH. 2012. Behavior of reoccurring PARAFAC components in fluorescent dissolved organic matter in natural and engineered systems: A critical review. Environmental Science \& Technology 46:2006-2017. DOI: 10.1021/es2043504.

Jackowicz-Korczyński M, Christensen TR, Bäckstrand K, Crill PM, Friborg T, Mastepanov M, Ström L. 2010. Annual cycle of methane emission from a subarctic peatland. Journal of Geophysical Research 115:G02009. DOI: 10.1029/2008JG000913.

Jansen J, Thornton BF, Cortes A, Snöälv J, Wik M, MacIntyre S, Crill PM. 2019a. Drivers of diffusive lake $\mathrm{CH}_{4}$ emissions on daily to multi-year time scales. Biogeosciences Discussions. DOI: 10.5194/bg-2019-322.

Jansen J, Thornton BF, Jammet MM, Wik M, Cortés A, Friborg T, Maclntyre S, Crill PM. 2019b. Climate-sensitive controls on large spring emissions of $\mathrm{CH}_{4}$ and $\mathrm{CO}_{2}$ from northern lakes. Journal of Geophysical Research: Biogeosciences 124:2379-2399. DOI: 10.1029/2019JG005094.

Johansson T, Malmer N, Crill PM, Friborg T, Åkerman JH, Mastepanov M, Christensen TR. 2006. Decadal vegetation changes in a northern peatland, greenhouse gas fluxes and net radiative forcing. Global Change Biology 12:2352-2369. DOI: 10.1111/j.13652486.2006.01267.x.

Jonasson C, Johansson M, Christensen TR (eds.). 2012. Special Report: Festschrift in honor of Terry V. Callaghan. AMBIO 41:175-313.

Jonasson C, Sonesson M, Christensen TR, Callaghan TV. 2012. Environmental monitoring and research in the Abisko area-an overview. AMBIO 41:178-186. DOI: 10.1007/s13280012-0301-6.

Jones M, O'Brien M, Mecum B, Boettiger C, Schildhauer M, Maier M, Whiteaker T, Earl S, Chong S. 2019. Ecological Metadata Language version 2.2.0. KNB Data Repository.

Kokfelt U, Reuss N, Struyf E, Sonesson M, Rundgren M, Skog G, Rosén P, Hammarlund D. 2010. Wetland development, permafrost history and nutrient cycling inferred from late Holocene peat and lake sediment records in subarctic Sweden. Journal of Paleolimnology 44:327-342. DOI: 10.1007/s10933-010-9406-8.

Kokfelt U, Rosén P, Schoning K, Christensen TR, Förster J, Karlsson J, Reuss N, Rundgren M, Callaghan TV, Jonasson C, Hammarlund D. 2009. Ecosystem responses to increased precipitation and permafrost decay in subarctic Sweden inferred from peat and lake

Peer] reviewing PDF | (2019:10:42335:1:1:NEW 22 May 2020) 
827

828

829

830

831

832

833

834

835

836

837

838

839

840

841

842

843

844

845

846

847

848

849

850

851

852

853

854

855

856

857

858

859

860

861

862

863

864

865 sediments. Global Change Biology 15:1652-1663. DOI: 10.1111/j.1365-

2486.2009.01880.x.

Leinonen R, Sugawara H, Shumway M, on behalf of the International Nucleotide Sequence Database Collaboration. 2011. The Sequence Read Archive. Nucleic Acids Research 39:D19-D21. DOI: 10.1093/nar/gkq1019.

Malhotra A, Moore TR, Limpens J, Roulet NT. 2018. Post-thaw variability in litter decomposition best explained by microtopography at an ice-rich permafrost peatland. Arctic, Antarctic, and Alpine Research 50:e1415622. DOI: 10.1080/15230430.2017.1415622.

Malhotra A, Roulet NT. 2015. Environmental correlates of peatland carbon fluxes in a thawing landscape: do transitional thaw stages matter? Biogeosciences 12:3119-3130. DOI: 10.5194/bg-12-3119-2015.

Malmer N, Johansson T, Olsrud M, Christensen TR. 2005. Vegetation, climatic changes and net carbon sequestration in a North-Scandinavian subarctic mire over 30 years. Global Change Biology 11:1895-1909. DOI: 10.1111/j.1365-2486.2005.01042.x.

Manzoni C, Kia DA, Vandrovcova J, Hardy J, Wood NW, Lewis PA, Ferrari R. 2018. Genome, transcriptome and proteome: the rise of omics data and their integration in biomedical sciences. Briefings in Bioinformatics 19:286-302. DOI: 10.1093/bib/bbw114.

Martens L, Hermjakob H, Jones P, Adamski M, Taylor C, States D, Gevaert K, Vandekerckhove J, Apweiler R. 2005. PRIDE: The proteomics identifications database. Proteomics 5:3537-3545. DOI: 10.1002/pmic.200401303.

Martinez MA, Woodcroft BJ, Ignacio Espinoza JC, Zayed AA, Singleton CM, Boyd JA, Li Y-F, Purvine S, Maughan H, Hodgkins SB, Anderson D, Sederholm M, Temperton B, Bolduc B, IsoGenie Project Coordinators, Saleska SR, Tyson GW, Rich VI. 2019. Discovery and ecogenomic context of a global Caldiserica-related phylum active in thawing permafrost, Candidatus Cryosericota phylum nov., Ca. Cryosericia class nov., Ca. Cryosericales ord. nov., Ca. Cryosericaceae fam. nov., comprising the four species Cryosericum septentrionale gen. nov. sp. nov., Ca. C. hinesii sp. nov., Ca. C. odellii sp. nov., Ca. C. terrychapinii sp. nov. Systematic and Applied Microbiology 42:54-66. DOI: 10.1016/j.syapm.2018.12.003.

McCalley CK, Woodcroft BJ, Hodgkins SB, Wehr RA, Kim E-H, Mondav R, Crill PM, Chanton JP, Rich VI, Tyson GW, Saleska SR. 2014. Methane dynamics regulated by microbial community response to permafrost thaw. Nature 514:478-481. DOI: 10.1038/nature13798.

Michener WK, Jones MB. 2012. Ecoinformatics: supporting ecology as a data-intensive science. Trends in Ecology \& Evolution 27:85-93. DOI: 10.1016/j.tree.2011.11.016.

Miller JJ. 2013. Graph database applications and concepts with Neo4j. In: SAIS 2013 Proceedings. Atlanta, GA, USA, 141-147.

Mondav R, McCalley CK, Hodgkins SB, Frolking S, Saleska SR, Rich VI, Chanton JP, Crill PM. 2017. Microbial network, phylogenetic diversity and community membership in the active

Peer] reviewing PDF | (2019:10:42335:1:1:NEW 22 May 2020) 
866

867

868

869

870

871

872

873

874

875

876

877

878

879

880

881

882

883

884

885

886

887

888

889

890

891

892

893

894

895

896

897

898

899

900

901

902

903

904

layer across a permafrost thaw gradient. Environmental Microbiology 19:3201-3218. DOI: 10.1111/1462-2920.13809.

Mondav R, Woodcroft BJ, Kim E-H, McCalley CK, Hodgkins SB, Crill PM, Chanton J, Hurst GB, VerBerkmoes NC, Saleska SR, Hugenholtz P, Rich VI, Tyson GW. 2014. Discovery of a novel methanogen prevalent in thawing permafrost. Nature Communications 5:3212. DOI: $10.1038 /$ ncomms4212.

Neo4j. 2020.Relational Databases vs. Graph Databases: A Comparison. Available at https://neo4j.com/developer/graph-db-vs-rdbms/ (accessed April 18, 2020).

Palace M, Herrick C, DelGreco J, Finnell D, Garnello A, McCalley C, McArthur K, Sullivan F, Varner R. 2018. Determining subarctic peatland vegetation using an unmanned aerial system (UAS). Remote Sensing 10:1498. DOI: 10.3390/rs10091498.

Perez-Arriaga MO, Wilson S, Williams KP, Schoeniger J, Waymire RL, Powell AJ. 2015. Omics Metadata Management Software (OMMS). Bioinformation 11:165-172. DOI: 10.6026/97320630011165.

Perryman CR, McCalley CK, Malhotra A, Fahnestock MF, Kashi NN, Bryce JG, Giesler R, Varner RK. 2020. Thaw transitions and redox conditions drive methane oxidation in a permafrost peatland. Journal of Geophysical Research: Biogeosciences 125:e2019JG005526. DOI: 10.1029/2019JG005526.

Peters DP, Groffman PM, Nadelhoffer KJ, Grimm NB, Collins SL, Michener WK, Huston MA. 2008. Living in an increasingly connected world: a framework for continental-scale environmental science. Frontiers in Ecology and the Environment 6:229-237. DOI: 10.1890/070098.

Rambold G, Yilmaz P, Harjes J, Klaster S, Sanz V, Link A, Glöckner FO, Triebel D. 2019. Metaomics data and collection objects (MOD-CO): a conceptual schema and data model for processing sample data in meta-omics research. Database 2019:baz002. DOI: 10.1093/database/baz002.

Ray S, Gebre S, Fogle H, Berrios DC, Tran PB, Galazka JM, Costes SV. 2019. GeneLab: Omics database for spaceflight experiments. Bioinformatics 35:1753-1759. DOI: 10.1093/bioinformatics/bty884.

Rohart F, Gautier B, Singh A, Lê Cao K-A. 2017. mixOmics: An R package for 'omics feature selection and multiple data integration. PLOS Computational Biology 13:e1005752. DOI: 10.1371/journal.pcbi.1005752.

Rose KC, Graves RA, Hansen WD, Harvey BJ, Qiu J, Wood SA, Ziter C, Turner MG. 2017. Historical foundations and future directions in macrosystems ecology. Ecology Letters 20:147-157. DOI: 10.1111/ele.12717.

Roux S, Trubl G, Goudeau D, Nath N, Couradeau E, Ahlgren NA, Zhan Y, Marsan D, Chen F, Fuhrman JA, Northen TR, Sullivan MB, Rich VI, Malmstrom RR, Eloe-Fadrosh EA. 2019. Optimizing de novo genome assembly from PCR-amplified metagenomes. PeerJ 7:e6902. DOI: 10.7717/peerj.6902. 
905

906

907

908

909

910

911

912

913

914

915

916

917

918

919

920

921

922

923

924

925

926

927

928

929

930

931

932

933

934

935

936

937

938

939

940

941

942

943

944

945

Sansone S-A, Rocca-Serra P, Field D, Maguire E, Taylor C, Hofmann O, Fang H, Neumann S, Tong W, Amaral-Zettler L, Begley K, Booth T, Bougueleret L, Burns G, Chapman B, Clark T, Coleman L-A, Copeland J, Das S, de Daruvar A, de Matos P, Dix I, Edmunds S, Evelo CT, Forster MJ, Gaudet P, Gilbert J, Goble C, Griffin JL, Jacob D, Kleinjans J, Harland L, Haug K, Hermjakob H, Sui SJH, Laederach A, Liang S, Marshall S, McGrath A, Merrill E, Reilly D, Roux M, Shamu CE, Shang CA, Steinbeck C, Trefethen A, Williams-Jones B, Wolstencroft K, Xenarios I, Hide W. 2012. Toward interoperable bioscience data. Nature Genetics 44:121-126. DOI: 10.1038/ng.1054.

Singleton CM, McCalley CK, Woodcroft BJ, Boyd JA, Evans PN, Hodgkins SB, Chanton JP, Frolking S, Crill PM, Saleska SR, Rich VI, Tyson GW. 2018. Methanotrophy across a natural permafrost thaw environment. The ISME Journal 12:2544-2558. DOI: 10.1038/s41396-018-0065-5.

Sujansky W. 2001. Heterogeneous database integration in biomedicine. Journal of Biomedical Informatics 34:285-298. DOI: 10.1006/jbin.2001.1024.

Symons S, Nieselt K. 2011. MGV: a generic graph viewer for comparative omics data. Bioinformatics 27:2248-2255. DOI: 10.1093/bioinformatics/btr351.

Tfaily MM, Hodgkins S, Podgorski DC, Chanton JP, Cooper WT. 2012. Comparison of dialysis and solid-phase extraction for isolation and concentration of dissolved organic matter prior to Fourier transform ion cyclotron resonance mass spectrometry. Analytical and Bioanalytical Chemistry 404:447-457. DOI: 10.1007/s00216-012-6120-6.

Triebel D, Hagedorn G, Rambold G. 2012. An appraisal of megascience platforms for biodiversity information. MycoKeys 5:45-63. DOI: 10.3897/mycokeys.5.4302.

Trubl G, Jang HB, Roux S, Emerson JB, Solonenko N, Vik DR, Solden L, Ellenbogen J, Runyon AT, Bolduc B, Woodcroft BJ, Saleska SR, Tyson GW, Wrighton KC, Sullivan MB, Rich VI. 2018. Soil viruses are underexplored players in ecosystem carbon processing. mSystems 3:e00076-18. DOI: 10.1128/mSystems.00076-18.

Trubl G, Roux S, Solonenko N, Li Y-F, Bolduc B, Rodríguez-Ramos J, Eloe-Fadrosh EA, Rich VI, Sullivan MB. 2019. Towards optimized viral metagenomes for double-stranded and single-stranded DNA viruses from challenging soils. PeerJ 7:e7265. DOI: 10.7717/peerj.7265.

Trubl G, Solonenko N, Chittick L, Solonenko SA, Rich VI, Sullivan MB. 2016. Optimization of viral resuspension methods for carbon-rich soils along a permafrost thaw gradient. PeerJ 4:e1999. DOI: 10.7717/peerj.1999.

Vizcaíno JA, Csordas A, del-Toro N, Dianes JA, Griss J, Lavidas I, Mayer G, Perez-Riverol Y, Reisinger F, Ternent T, Xu Q-W, Wang R, Hermjakob H. 2016. 2016 update of the PRIDE database and its related tools. Nucleic Acids Research 44:D447-D456. DOI: 10.1093/nar/gkv1145.

Vizcaíno JA, Deutsch EW, Wang R, Csordas A, Reisinger F, Ríos D, Dianes JA, Sun Z, Farrah T, Bandeira N, Binz P-A, Xenarios I, Eisenacher M, Mayer G, Gatto L, Campos A, Chalkley RJ, Kraus H-J, Albar JP, Martinez-Bartolomé S, Apweiler R, Omenn GS, Martens L, Jones AR, Hermjakob H. 2014. ProteomeXchange provides globally

Peer] reviewing PDF | (2019:10:42335:1:1:NEW 22 May 2020) 
946

947

948

949

950

951

952

953

954

955

956

957

958

959

960

961

962

963

964

965

966

967

968

969

970

971

972

973

974

975

976

977

978

979

980

981

982

983

984

985

986

987

988

coordinated proteomics data submission and dissemination. Nature Biotechnology 32:223-226. DOI: 10.1038/nbt.2839.

Wik M, Crill PM, Varner RK, Bastviken D. 2013. Multiyear measurements of ebullitive methane flux from three subarctic lakes. Journal of Geophysical Research: Biogeosciences 118:1307-1321. DOI: 10.1002/jgrg.20103.

Wik M, Johnson JE, Crill PM, DeStasio JP, Erickson L, Halloran MJ, Fahnestock MF, Crawford MK, Phillips SC, Varner RK. 2018. Sediment characteristics and methane ebullition in three subarctic lakes. Journal of Geophysical Research: Biogeosciences 123:23992411. DOI: $10.1029 / 2017 J G 004298$.

Wilkinson MD, Dumontier M, Aalbersberg ljJ, Appleton G, Axton M, Baak A, Blomberg N, Boiten J-W, da Silva Santos LB, Bourne PE, Bouwman J, Brookes AJ, Clark T, Crosas M, Dillo I, Dumon O, Edmunds S, Evelo CT, Finkers R, Gonzalez-Beltran A, Gray AJG, Groth P, Goble C, Grethe JS, Heringa J, 't Hoen PAC, Hooft R, Kuhn T, Kok R, Kok J, Lusher SJ, Martone ME, Mons A, Packer AL, Persson B, Rocca-Serra P, Roos M, van Schaik R, Sansone S-A, Schultes E, Sengstag T, Slater T, Strawn G, Swertz MA, Thompson M, van der Lei J, van Mulligen E, Velterop J, Waagmeester A, Wittenburg P, Wolstencroft K, Zhao J, Mons B. 2016. The FAIR Guiding Principles for scientific data management and stewardship. Scientific Data 3:160018. DOI: 10.1038/sdata.2016.18.

Wilson RM, Neumann RB, Crossen KB, Raab NM, Hodgkins SB, Saleska SR, Bolduc B, Woodcroft BJ, Tyson GW, Chanton JP, Rich VI. 2019. Microbial community analyses inform geochemical reaction network models for predicting pathways of greenhouse gas production. Frontiers in Earth Science 7:59. DOI: 10.3389/feart.2019.00059.

Wilson RM, Tfaily MM. 2018. Advanced molecular techniques provide new rigorous tools for characterizing organic matter quality in complex systems. Journal of Geophysical Research: Biogeosciences 123:1790-1795. DOI: 10.1029/2018JG004525.

Wilson RM, Tfaily MM, Rich VI, Keller JK, Bridgham SD, Zalman CM, Meredith L, Hanson PJ, Hines M, Pfeifer-Meister L, Saleska SR, Crill P, Cooper WT, Chanton JP, Kostka JE. 2017. Hydrogenation of organic matter as a terminal electron sink sustains high $\mathrm{CO}_{2}: \mathrm{CH}_{4}$ production ratios during anaerobic decomposition. Organic Geochemistry 112:22-32. DOI: 10.1016/j.orggeochem.2017.06.011.

Woodcroft BJ, Singleton CM, Boyd JA, Evans PN, Emerson JB, Zayed AAF, Hoelzle RD, Lamberton TO, McCalley CK, Hodgkins SB, Wilson RM, Purvine SO, Nicora CD, Li C, Frolking S, Chanton JP, Crill PM, Saleska SR, Rich VI, Tyson GW. 2018. Genomecentric view of carbon processing in thawing permafrost. Nature 560:49-54. DOI: 10.1038/s41586-018-0338-1.

Yilmaz P, Kottmann R, Field D, Knight R, Cole JR, Amaral-Zettler L, Gilbert JA, Karsch-Mizrachi I, Johnston A, Cochrane G, Vaughan R, Hunter C, Park J, Morrison N, Rocca-Serra P, Sterk P, Arumugam M, Bailey M, Baumgartner L, Birren BW, Blaser MJ, Bonazzi V, Booth T, Bork P, Bushman FD, Buttigieg PL, Chain PSG, Charlson E, Costello EK, HuotCreasy H, Dawyndt P, DeSantis T, Fierer N, Fuhrman JA, Gallery RE, Gevers D, Gibbs RA, Gil IS, Gonzalez A, Gordon JI, Guralnick R, Hankeln W, Highlander S, Hugenholtz P, Jansson J, Kau AL, Kelley ST, Kennedy J, Knights D, Koren O, Kuczynski J, Kyrpides N, Larsen R, Lauber CL, Legg T, Ley RE, Lozupone CA, Ludwig W, Lyons D, Maguire E,

Peer] reviewing PDF | (2019:10:42335:1:1:NEW 22 May 2020) 
989

990

991

992

993

994

995

996

997

998

Methé BA, Meyer F, Muegge B, Nakielny S, Nelson KE, Nemergut D, Neufeld JD, Newbold LK, Oliver AE, Pace NR, Palanisamy G, Peplies J, Petrosino J, Proctor L, Pruesse E, Quast C, Raes J, Ratnasingham S, Ravel J, Relman DA, Assunta-Sansone S, Schloss PD, Schriml L, Sinha R, Smith MI, Sodergren E, Spor A, Stombaugh J, Tiedje JM, Ward DV, Weinstock GM, Wendel D, White O, Whiteley A, Wilke A, Wortman JR, Yatsunenko T, Glöckner FO. 2011. Minimum information about a marker gene sequence (MIMARKS) and minimum information about any $(\mathrm{x})$ sequence (MIxS) specifications. Nature Biotechnology 29:415-420. DOI: 10.1038/nbt.1823.

Yoon B-H, Kim S-K, Kim S-Y. 2017. Use of graph database for the integration of heterogeneous biological data. Genomics \& Informatics 15:19-27. DOI: 10.5808/GI.2017.15.1.19.

999 


\section{Table $\mathbf{1}$ (on next page)}

Summary of dataset types in the IsoGenieDB.

Listed dataset types include citations of IsoGenie and related project papers that use each type of dataset, and those marked with an " $X$ " are available in the public portion of the DB. Abbreviations: ANS = Abisko Naturvetenskapliga Station, NDVI = normalized difference vegetation index, $\mathrm{DOC}=$ dissolved organic carbon, $\mathrm{TN}=$ total nitrogen, $\mathrm{VFAs}=$ volatile fatty acids, $\mathrm{DIC}=$ dissolved inorganic carbon, FT-ICR MS = Fourier transform ion cyclotron resonance mass spectrometry, DOM = dissolved organic matter, UV/Vis = ultraviolet/visible absorption spectroscopy, EEMS = excitation-emission matrix spectroscopy, FTIR = Fourier transform infrared spectroscopy, MAGs = metagenome-assembled genomes. 
1 Table 1. Summary of dataset types in the IsoGenieDB. Listed dataset types include citations of IsoGenie and 2 related project papers that use each type of dataset, and those marked with an " $X$ " are available in the public portion 3 of the DB. Abbreviations: ANS = Abisko Naturvetenskapliga Station, NDVI = normalized difference vegetation index, $4 \mathrm{DOC}=$ dissolved organic carbon, $\mathrm{TN}=$ total nitrogen, VFAs = volatile fatty acids, $\mathrm{DIC}=$ dissolved inorganic carbon, 5 FT-ICR MS = Fourier transform ion cyclotron resonance mass spectrometry, DOM = dissolved organic matter, UV/Vis 6 = ultraviolet/visible absorption spectroscopy, EEMS = excitation-emission matrix spectroscopy, FTIR = Fourier 7 transform infrared spectroscopy, MAGs = metagenome-assembled genomes.

\begin{tabular}{|c|c|c|}
\hline & Public? & References \\
\hline \multicolumn{3}{|l|}{ Sampling information: } \\
\hline $\begin{array}{l}\text { Coring metadata (sampling dates, locations, } \\
\text { depths, samples taken) }\end{array}$ & $\mathrm{X}$ & numerous \\
\hline $\begin{array}{l}\text { Field data (water table and active layer } \\
\text { depths, } \mathrm{pH} \text {, and air and soil temperatures at } \\
\text { time of coring) }\end{array}$ & $\mathrm{X}$ & numerous \\
\hline \multicolumn{3}{|l|}{\begin{tabular}{|l} 
Weather and other environmental data: \\
\end{tabular}} \\
\hline $\begin{array}{l}\text { ANS daily and hourly weather summaries } \\
\text { (including daily weather from 1913-present) }\end{array}$ & & $\begin{array}{l}\text { Callaghan et al. (2010); Jonasson, Johansson \& } \\
\text { Christensen (2012); Jonasson et al. (2012); } \\
\text { numerous others }\end{array}$ \\
\hline $\begin{array}{l}\text { Mire weather, soil temperature and moisture } \\
\text { profiles, heat fluxes, and NDVI (continuous) }\end{array}$ & & Jansen et al., (2019a,b); Garnello (2017) \\
\hline Lake water temperature profiles (continuous) & $\mathrm{X}$ & Wik et al. (2013) \\
\hline \multicolumn{3}{|l|}{ Gas fluxes: } \\
\hline $\begin{array}{l}\text { Total hydrocarbon, } \mathrm{CH}_{4} \text {, and } \mathrm{CO}_{2} \text { fluxes from } \\
\text { autochambers }\end{array}$ & $\mathrm{X}$ & $\begin{array}{l}\text { Bäckstrand et al. (2008a,b, 2010); Jackowicz- } \\
\text { Korczyński et al. (2010); Holst et al. (2010) }\end{array}$ \\
\hline $\begin{array}{l}\delta^{13} \mathrm{C} \text { values of } \mathrm{CH}_{4} \text { and } \mathrm{CO}_{2} \text { fluxes from } \\
\text { autochambers }\end{array}$ & & McCalley et al. (2014) \\
\hline $\begin{array}{l}\text { Thaw pond bubble fluxes and associated } \\
\text { temperatures }\end{array}$ & $\mathrm{X}$ & Burke et al. (2019) \\
\hline \multicolumn{3}{|l|}{ Terrestrial subsurface geochemistry: } \\
\hline $\mathrm{CH}_{4}$ and $\mathrm{CO}_{2}$ concentrations and $\delta^{13} \mathrm{C}$ values & $\mathrm{X}$ & $\begin{array}{l}\text { McCalley et al. (2014); Hodgkins et al. (2015); } \\
\text { Hodgkins (2016); Perryman et al. (2020) }\end{array}$ \\
\hline $\begin{array}{l}\text { Dissolved species concentrations (DOC, TN, } \\
\text { acetate and other VFAs, } \mathrm{O}_{2}, \mathrm{PO}_{4}{ }^{3-}, \mathrm{SO}_{4}{ }^{2-}, \\
\left.\mathrm{NO}_{3}{ }^{-}, \mathrm{NH}_{3}, \mathrm{Mn}, \mathrm{Fe}, \mathrm{Ca}, \mathrm{Mg}\right)\end{array}$ & $\mathrm{X}$ & Hodgkins (2016); Perryman et al. (2020) \\
\hline Peat water content & $\mathrm{X}$ & Hodgkins (2016) \\
\hline \multicolumn{3}{|l|}{ Peat bulk density } \\
\hline $\begin{array}{l}\text { Peat } \mathrm{C} \text { and } \mathrm{N} \text { concentrations, } \delta^{13} \mathrm{C} \text { and } \delta^{15} \mathrm{~N} \text {, } \\
\text { and } \mathrm{C} / \mathrm{N} \text { ratios }\end{array}$ & $\mathrm{X}$ & Hodgkins et al. (2014); Hodgkins (2016) \\
\hline Radiocarbon ages of peat and DIC & $\mathrm{X}$ & Hodgkins (2016) \\
\hline FT-ICR MS & $\begin{array}{l}\text { X (summarized } \\
\text { indices) }\end{array}$ & $\begin{array}{l}\text { Tfaily et al. (2012); Hodgkins et al. (2014, 2016); } \\
\text { Hodgkins (2016); Wilson et al. (2017); Wilson \& } \\
\text { Tfaily (2018) }\end{array}$ \\
\hline DOM optical properties (UV/Vis and EEMS) & $\begin{array}{l}\text { X (summarized } \\
\text { indices) }\end{array}$ & Hodgkins (2016); Hodgkins et al. (2016) \\
\hline Peat FTIR & $\begin{array}{l}\text { X (summarized } \\
\text { indices) }\end{array}$ & Hodgkins et al. $(2014,2018)$ \\
\hline $\begin{array}{l}\text { Results from peat incubations }\left(\mathrm{CH}_{4} \text { and } \mathrm{CO}_{2}\right. \\
\left.\text { production and } \delta^{13} \mathrm{C} \text { values }\right)\end{array}$ & $\begin{array}{l}\text { X (summarized } \\
\text { indices) }\end{array}$ & $\begin{array}{l}\text { Hodgkins et al. (2014, 2015); Hodgkins (2016); } \\
\text { Wilson et al. (2017, 2019); Perryman et al. } \\
(2020)\end{array}$ \\
\hline
\end{tabular}




\begin{tabular}{|c|c|c|}
\hline \multicolumn{3}{|l|}{ Microbial and viral sequencing: } \\
\hline 16S rRNA amplicons $(\sim 100)$ & $\mathrm{X}$ & $\begin{array}{l}\text { McCalley et al. (2014); Deng et al. (2017); } \\
\text { Mondav et al. (2017); Martinez et al. (2019); } \\
\text { Wilson et al. (2019) }\end{array}$ \\
\hline Metagenomes ( 375) & $\mathrm{X}$ & $\begin{array}{l}\text { Mondav \& Woodcroft et al. (2014); Singleton et } \\
\text { al. (2018); Woodcroft \& Singleton et al. (2018); } \\
\text { Martinez et al. (2019) }\end{array}$ \\
\hline Metatransciptomes (24) & $\mathrm{X}$ & $\begin{array}{l}\text { Singleton et al. (2018); Woodcroft \& Singleton et } \\
\text { al. (2018); Martinez et al. (2019) }\end{array}$ \\
\hline Metaproteomes (16) & $\mathrm{X}$ & $\begin{array}{l}\text { Mondav \& Woodcroft et al. (2014); Woodcroft \& } \\
\text { Singleton et al. (2018); Martinez et al. (2019) }\end{array}$ \\
\hline Viromes (65) & $\mathrm{X}$ & $\begin{array}{l}\text { Trubl et al. (2016, 2018, 2019); Roux et al. } \\
(2019)\end{array}$ \\
\hline $\begin{array}{l}\text { Viral population contigs mined from } \\
\text { metagenomes }\end{array}$ & $\mathrm{X}$ & Emerson et al. (2018) \\
\hline MAGs ( 1600) & $\mathrm{X}$ & $\begin{array}{l}\text { Singleton et al. (2018); Woodcroft \& Singleton et } \\
\text { al. (2018); Martinez et al. (2019) }\end{array}$ \\
\hline $\begin{array}{l}\text { Lake sediment microbial community } \\
\text { composition (based on } 16 \mathrm{~S} \text { rRNA amplicons, } \\
\text { metagenomes, and MAGs) }\end{array}$ & $\mathrm{X}$ & Emerson et al. (in review) \\
\hline \multicolumn{3}{|l|}{ Plant-associated data: } \\
\hline Ultra-high-resolution drone imagery & $\begin{array}{l}\text { X (as overlay on } \\
\text { Map Interface) }\end{array}$ & Palace et al. (2018) \\
\hline $\begin{array}{l}\text { Rhizosphere and phyllosphere microbial } \\
\text { community composition (iTag-based) }\end{array}$ & $\mathrm{X}$ & Hough et al. (in review) \\
\hline \multicolumn{3}{|l|}{ Modeling: } \\
\hline Ecosys model input data, code, and outputs & $\mathrm{X}$ & Chang et al. $(2019 b, a)$ \\
\hline
\end{tabular}




\section{Table 2 (on next page)}

Data quality levels, used to denote quality control (QC) and processing status. 
1 Table 2. Data quality levels, used to denote quality control (QC) and processing status.

\begin{tabular}{|l|l|l|}
\hline $\begin{array}{l}\text { Quality } \\
\text { Level }\end{array}$ & Description & $\begin{array}{l}\text { Example (using geochemical } \\
\text { spectral data, such as FTIR) }\end{array}$ \\
\hline 0 & Raw data. & $\begin{array}{l}\text { Raw, unprocessed spectra directly } \\
\text { from the instrument. }\end{array}$ \\
\hline 1 & $\begin{array}{l}\text { Data with basic QC. Internally consistent with } \\
\text { similar datasets from the same lab. }\end{array}$ & $\begin{array}{l}\text { Spectra with baseline corrections, and } \\
\text { chemical abundances derived } \\
\text { therefrom. }\end{array}$ \\
\hline 2 & $\begin{array}{l}\text { Data with extensive, externally-checked QC. In } \\
\text { addition to undergoing the QC necessary for } \\
\text { Quality 1, the data has also been reviewed for } \\
\text { external consistency with similar data from other } \\
\text { labs. }\end{array}$ & $\begin{array}{l}\text { Spectra with baseline corrections and } \\
\text { derived chemical abundances, which } \\
\text { have passed peer review for } \\
\text { publication in a manuscript. }\end{array}$ \\
\hline
\end{tabular}

2

3 


\section{Figure 1}

The IsoGenie Project's systems approach to characterizing carbon cycling, involving integration of diverse data spanning a broad range of spatial and temporal scales.

(A) General overview of project approach and dataset types arising (purple text), with screenshots, figures, or other images shown for select dataset types. Image sources (available on the IsoGenieDB website (https://isogenie-db.asc.ohio-state.edu): The FTIR spectrum figure (under "complex spectra...") is from Hodgkins (2016). All spreadsheet and text file screenshots are of files available on the Downloads page under similar headings. Photo credits: "sampling overview," Nicole Raab; "soil core," Virginia Rich; "species \& biomass profiling," Moira Hough; "ultrahigh resolution drone image," Michael Palace (Palace et al., 2018). (B) A more comprehensive list of dataset types oriented along spatial and temporal scale axes. Abbreviations: OTUs $=$ operational taxonomic units, MAGs $=$ metagenome assembled genomes, FT-ICR MS = Fourier transform ion cyclotron resonance mass spectrometry, LC MS/MS = liquid chromatography with tandem mass spectrometry. 

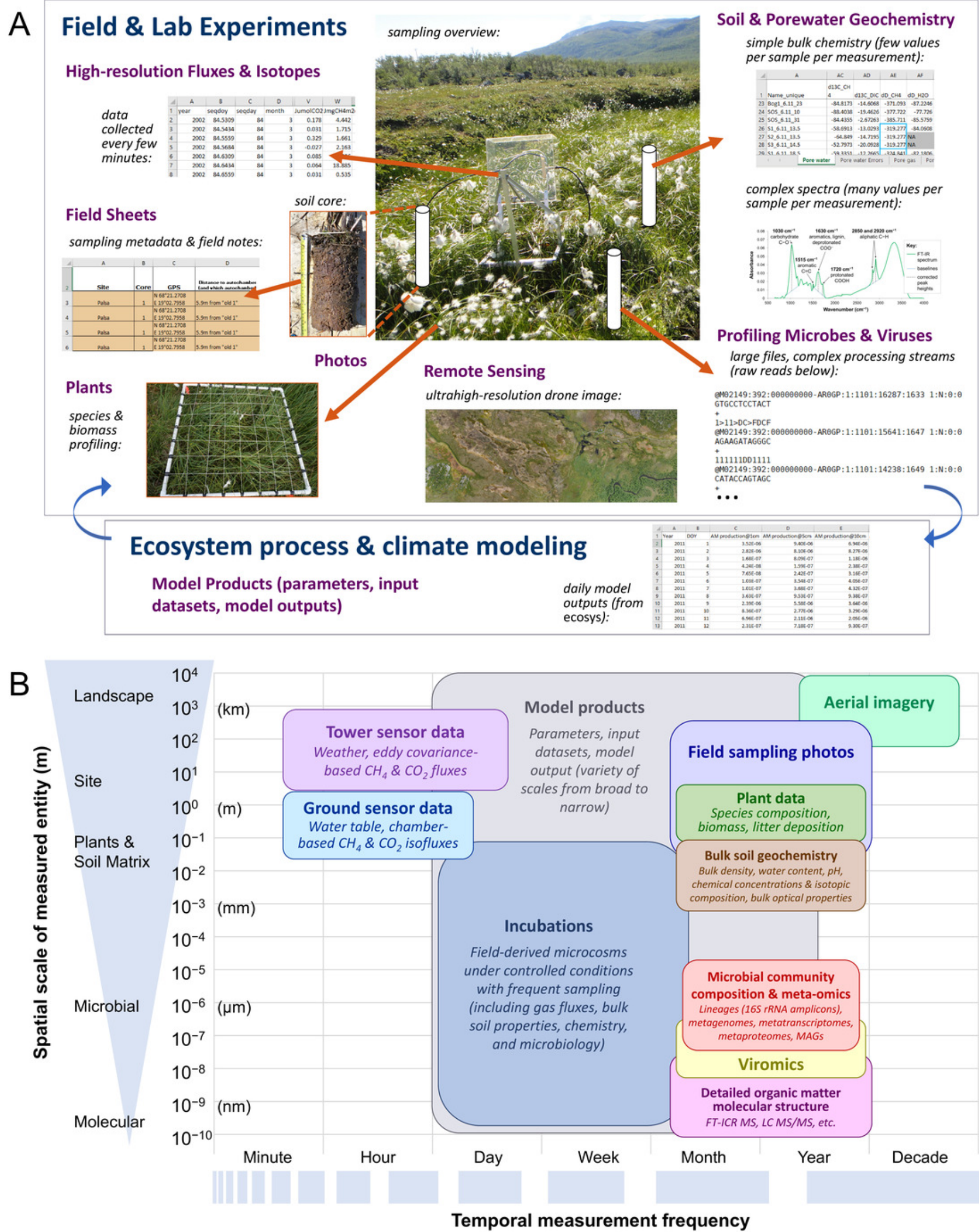


\section{Figure 2}

Browsing sites through the Map Interface on the IsoGenieDB website (https://isogenie-db.asc.ohio-state.edu/maps).

(A) Location of the IsoGenie Project site (Stordalen Mire), shown on the A2A-DB version of the Map Interface (https://a2a-db.asc.ohio-state.edu/maps) with four other comparator arctic peatland sites. (B) The IsoGenieDB Map Interface shows the core locations (color-coded by habitat type) overlain on an ultra-high-resolution drone image (Palace et al., 2018). (C) Each point includes a popup with the site and core name, sampling date, available data, and core images. Background maps: (A) ๑ 2019 Google, NASA, TerraMetrics; (B, C) ๑ 2019 Google, DigitalGlobe, Lantmäteriet/Metria. 

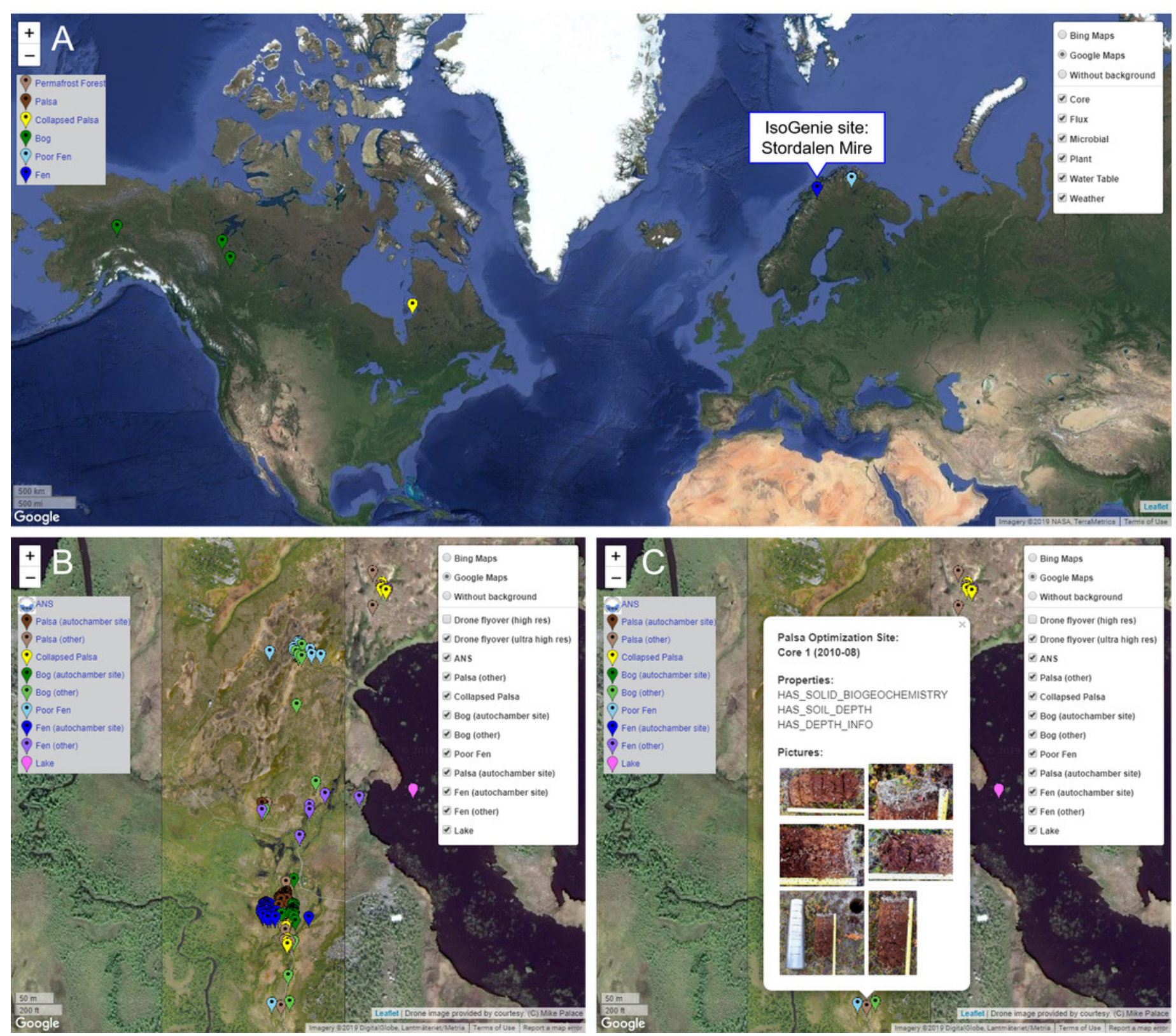


\section{Figure 3}

Basic node structure of the IsoGenieDB.

This structure is shown for three representative dataset types: lake temperature timeseries (blue), autochamber (green), and soil core data (yellow). Nodes used purely for spatial and temporal organization are in blue, data-containing nodes are purple, and nodes containing file metadata are in green. Relationship labels (shown for the first few relationships in the tree) follow a similar naming scheme throughout the database. Data are stored as key:value properties within the nodes (shown for the soil data), with special standardized properties (denoted with keys ending in "_") storing sampling metadata related to each node's spatialtemporal placement. These standardized properties are automatically inherited from "upstream" in the scale-organized tree, while file Metadata nodes include their own standardized properties. This entire structure can be queried simultaneously to find derived relationships among data from different branches of the database (illustrated with curved dotted teal arrows).

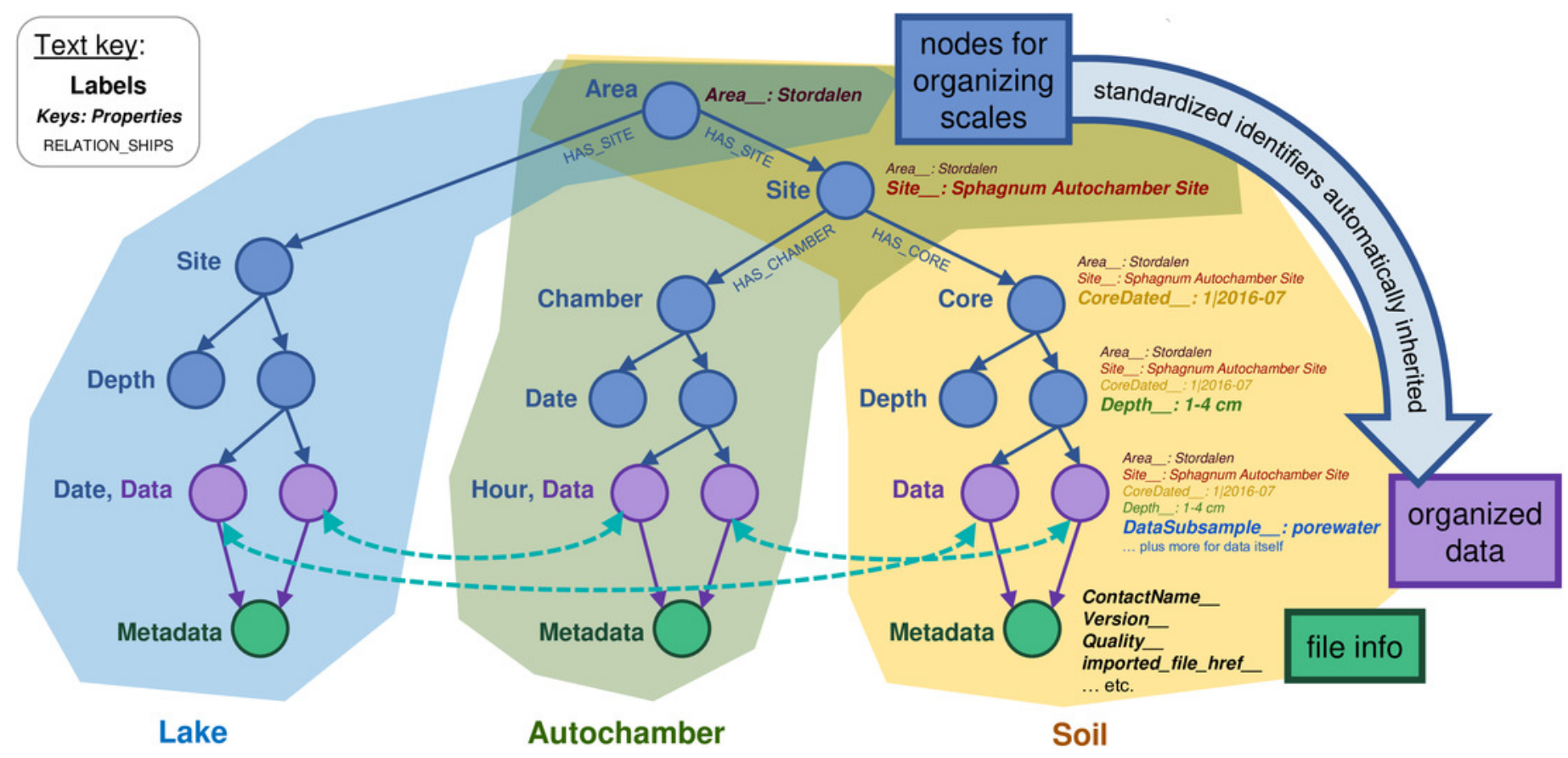




\section{Figure 4}

Database node structure for microbial sequencing data.

These datasets include very large, detailed nucleic and amino acid sequences at varying quality levels. Raw reads are quality-checked (QC'd) and then binned into contigs, which are then used to derive fundamental knowledge on microbial ecology via metagenomeassembled genomes (MAGs). The contigs and MAGs, in turn, can be separated into individual sequences (purple). The IsoGenieDB stores these variously processed datasets and data entities in a node/relationship network that maps to the data processing pipeline, with very large sequence files stored as links to flat files in combined Data/Metadata nodes (green). These combined nodes also have HAS_METADATA relationships originating from the Sequence nodes, consistent with the Data $\rightarrow$ Metadata node structure used for other types of datasets (Figure 3), in addition to HAS_SEQUENCE relationships pointing in the opposite direction to mirror the data processing order. "Collection" nodes are also used to group data originating from the same sample (blue), which acts as an additional organizational paradigm for cases where not all data processing steps available to build the full pipeline node structure. 
Node labels (in addition to those shown):

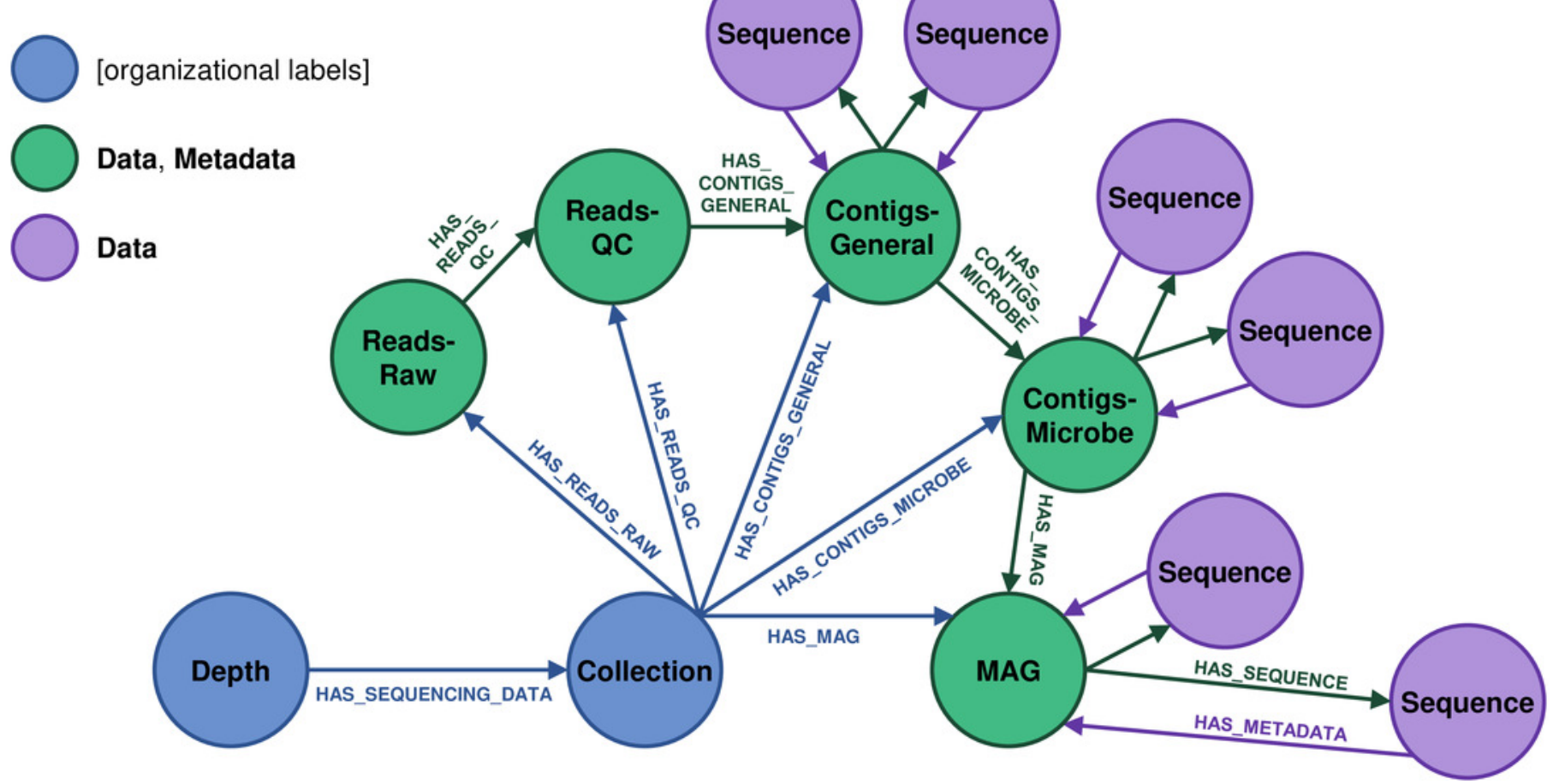




\section{Figure 5}

Integrated structure of the IsoGenieDB and A2A-DB.

A single unified graph database (overall Venn diagram) encompasses both the IsoGenieDB (yellow ellipse) and A2A-DB (blue ellipse). These databases share some of the same data (green region), a subset of which can be accessed by the general public (orange ellipse). Separate web portals (URLs under database names) provide the projects with access to their respective subsets of data, with public data access granted by the public-facing portions of each website. The access permissions for of any given node are controlled by labels (bold italic text), which are used to filter the results of queries as part of the back-end of each website's Querying page (for example, all queries from the A2A-DB web portal include a builtin filter that only returns those nodes with the label "A2A", and queries from the public web portals only return nodes with the label "Public"). 


\section{Unified Graph Database}

IsoGenieDB

https://isogenie-db.asc.ohio-state.edu/
A2A-DB

https://a2a-db.asc.ohio-state.edu/

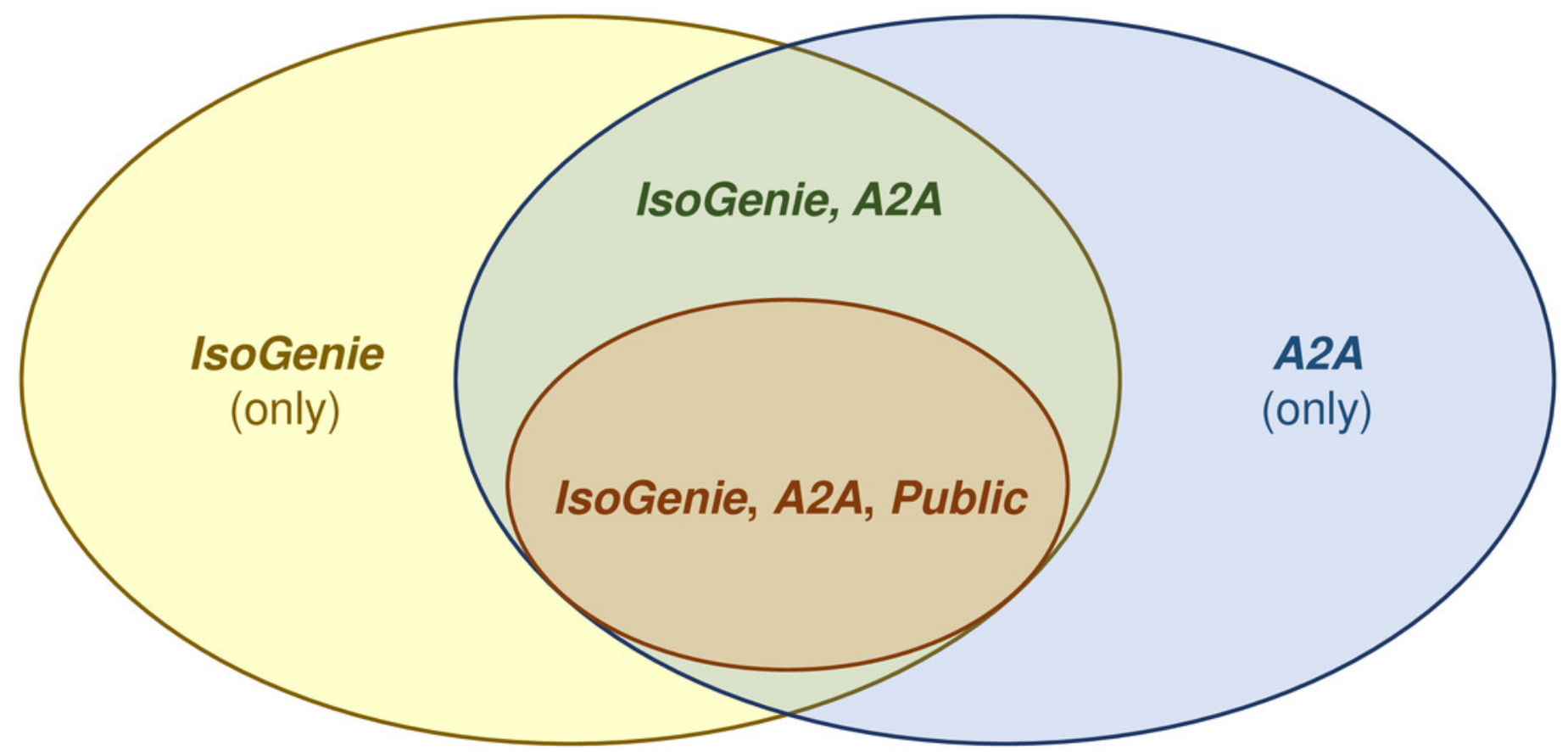

